\title{
Synucleins Regulate the Kinetics of Synaptic Vesicle Endocytosis
}

\author{
Karina J. Vargas, ${ }^{1,2}$ Sachin Makani, ${ }^{5}$ Taylor Davis, ${ }^{1,2}$ Christopher H. Westphal, ${ }^{2,3}$ Pablo E. Castillo, ${ }^{5}$ \\ and Sreeganga S. Chandra ${ }^{1,2,4}$ \\ ${ }^{1}$ Department of Neurology and 2 Program in Cellular Neuroscience, Neurodegeneration and Repair, Yale University, New Haven, Connecticut 06536, \\ ${ }^{3}$ Department of Cell Biology and ${ }^{4}$ Department of Molecular Cellular and Developmental Biology Yale University, New Haven, Connecticut 06519, and \\ ${ }^{5}$ Dominick P. Purpura Department of Neuroscience, Albert Einstein College of Medicine, Bronx, New York 10461
}

Genetic and pathological studies link $\alpha$-synuclein to the etiology of Parkinson's disease (PD), but the normal function of this presynaptic protein remains unknown. $\alpha$-Synuclein, an acidic lipid binding protein, shares high sequence identity with $\beta$-and $\gamma$-synuclein. Previous studies have implicated synucleins in synaptic vesicle (SV) trafficking, although the precise site of synuclein action continues to be unclear. Here we show, using optical imaging, electron microscopy, and slice electrophysiology, that synucleins are required for the fast kinetics of SV endocytosis. Slowed endocytosis observed in synuclein null cultures can be rescued by individually expressing mouse $\alpha$-, $\beta$-, or $\gamma$-synuclein, indicating they are functionally redundant. Through comparisons to dynamin knock-out synapses and biochemical experiments, we suggest that synucleins act at early steps of SV endocytosis. Our results categorize $\alpha$-synuclein with other familial PD genes known to regulate SV endocytosis, implicating this pathway in PD.

Key words: AP180; endocytosis; membrane bending; Parkinson's disease; presynaptic; synaptobrevin

\section{Introduction}

Strong genetic evidence links SNCA, the $\alpha$-synuclein gene, to familial Parkinson's disease (PD; Devine et al., 2011; Houlden and Singleton, 2012). Furthermore, increased expression of $\alpha$-synuclein is a risk factor for PD (Devine, 2011). $\alpha$-Synuclein is also the main protein in Lewy bodies, the signature pathology of PD (Spillantini et al., 1997). Hence, $\alpha$-synuclein is a prime therapeutic target for PD. It is therefore important to elucidate the physiological function of $\alpha$-synuclein and understand the consequences of lowering $\alpha$-synuclein levels for therapeutic purposes.

$\alpha$-Synuclein along with $\beta$ - and $\gamma$-synuclein constitute the synuclein protein family (Chandra, 2009). Synucleins have high sequence identity, especially in the N-terminal regions that bind acidic lipids. Synucleins are natively unfolded in solution, but adopt $\alpha$-helical conformations on membranes (Chandra et al.,

\footnotetext{
Received Nov. 13, 2013; revised June 4, 2014; accepted June 6, 2014

Author contributions: K.J.V., S.M., C.H.W., P.E.C., and S.S.C. designed research; K.J.V., S.M., T.D., C.H.W., and S.S.C. performed research; K.J.V., S.M., T.D., C.H.W., P.E.C., and S.S.C. analyzed data; K.J.V., S.M., C.H.W., P.E.C., and S.S.C. wrote the paper.

This work was supported by a fellowship from the Pew Foundation to K.J.V. and National Institute of Neurological Disorders and Stroke grants (R01 NS064963, NS083846) to S.S.C., C.H.W. was supported in part by National Institutes of Health grant T32GM7223. The study was financed by the Bumpus Foundation (S.S.C.), Anonymous Foundation (S.S.C.), National Institute on Drug Abuse Neuroproteomic Pilot Grant (5 P30 DA018343-07 to S.S.C.), and DA017392 (P.E.C.). We are grateful to Pietro De Camilli for helpful advice during the course of this study and for providing us with key reagents. We thank him, Art Horwich, Thomas Biederer, and members of our laboratory for critically reading this paper. We thank Louise Loucast, Yumiko Taguchi, and Becket Greten-Harrison for excellent technical assistance.

The authors declare no competing financial interests.

Correspondence should be addressed to Sreeganga S. Chandra, CNNR Program, Department of Neurology, Yale University, New Haven, CT, 06536. E-mail: sreeganga.chandra@yale.edu.

DOI:10.1523/JNEUROSCI.4787-13.2014

Copyright $\odot 2014$ the authors $\quad 0270-6474 / 14 / 349364-13 \$ 15.00 / 0$
}

2003; Jao et al., 2004; Ferreon et al., 2009). Through these conformational changes, synucleins can sense and generate membrane curvature (Varkey et al., 2010; Pranke et al., 2011; Mizuno et al., 2012; Westphal and Chandra, 2013). Congruent with these biochemical properties, studies in model organisms have consistently shown that $\alpha$-synuclein interferes with intracellular vesicle trafficking (Cooper et al., 2006; Scott and Roy, 2012). However, the pathways impacted differ in the various systems, making it difficult to determine the physiological function of $\alpha$-synuclein. One possible explanation for these discrepancies is that these model systems lack endogenous $\alpha$-synuclein, and overexpression leads to oligomerization and aberrant subcellular localization.

Synucleins are localized to synaptic vesicles (SVs) at presynaptic termini (Clayton and George, 1999), suggesting that synucleins may regulate the SV cycle. The major steps of the SV cycle include docking, priming, SV exocytosis, endocytosis, and refilling (Sudhof, 2004). Based on their biochemical characteristics, synucleins would be predicted to regulate SV exocytosis or endocytosis, the two steps that require membrane bending. Recently, the notion that $\alpha$-synuclein promotes SNARE complex assembly during exocytosis has gained prominence (Burré et al., 2010, 2012). However, new biophysical studies question this hypothesis, as native $\alpha$-synuclein either had no effect on SNAREmediated vesicle fusion in vitro or regulated fusion by modulating properties of the lipid bilayer (Darios et al., 2010; Ninkina et al., 2012; DeWitt and Rhoades, 2013; Diao et al., 2013). Furthermore, $\alpha$-synuclein oligomers inhibit SNARE-mediated fusion, indicating that the $\alpha$-synuclein-SNARE interaction is possibly related to the pathological function of $\alpha$-synuclein (Larsen et al., 2006; Choi et al., 2013). 

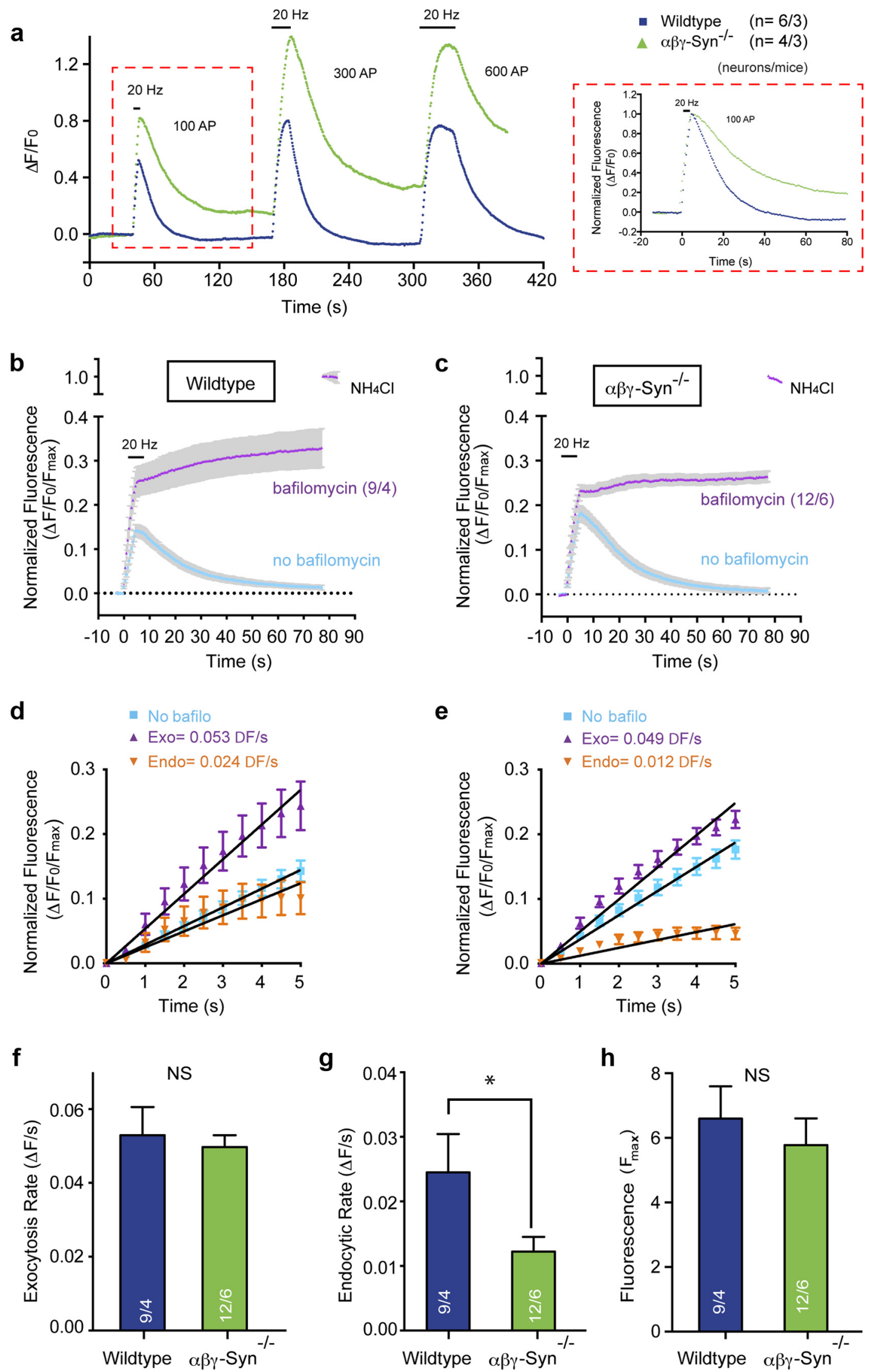

Figure 1. Synucleins regulate SV endocytosis. $a$, Average representative traces of spH fluorescence in wild-type and $\alpha \beta \gamma$-Syn ${ }^{-/-}$neurons. Neurons were stimulated three times (100 AP, 300 $\mathrm{AP}$, and $600 \mathrm{AP})$ at $20 \mathrm{~Hz}$ with an interval of $2 \mathrm{~min}$ between each stimulation. Average time constants of decay $(\tau)$ for wild-type $=15.6 \mathrm{~s}, 13.3 \mathrm{~s}, 17.8 \mathrm{~s}$, respectively, for $\alpha \beta \gamma$-Syn ${ }^{-/-}=36.1 \mathrm{~s}$, $35.6 \mathrm{~s}, 27.6 \mathrm{~s}$, respectively; $n=6$ neurons/3 independent experiments for wild-type and $n=4$ neurons/3 independent experiments for $\alpha \beta \gamma$-Syn ${ }^{-1-}$. (Figure legend continues.) 
In addition to SV exocytosis, previous studies have implied a number of roles for $\alpha$-synuclein throughout the SV cycle (Bendor et al., 2013), including endocytosis (Ben Gedalya et al., 2009), SV pool size (Cabin et al., 2002), SV mobilization (Nemani et al., 2010), and even trafficking between synapses (Scott and Roy, 2012). Together, the precise synaptic function(s) of synucleins continues to be unclear. Additionally, several of these studies were done using overexpression of human $\alpha$-synuclein, confusing what effects are related to the pathological versus physiological functions of $\alpha$-synuclein. Here, we took a loss-of-function approach to elucidate the physiological function of synucleins (Greten-Harrison et al., 2010). We examined SV cycling in synuclein null neurons and show that synucleins preferentially regulate SV endocytosis.

\section{Materials and Methods}

Mice. Generation and characterization of synuclein null $\left(\alpha \beta \gamma-\right.$ Syn $\left.^{-/-}\right)$ and DynDKO mice have been previously described (Ferguson et al., 2007; Greten-Harrison et al., 2010; Raimondi et al., 2011). DynDKO were a kind gift from Pietro De Camilli, Yale University. Mice were kept in accordance with an Institutional Animal Care and Use Committee approved animal protocol. The breeding strategy for the $\alpha \beta \gamma$-Syn ${ }^{-1-}$ mice used in this study is as described previously (Greten-Harrison et al., 2010). All mice used in this study are on a C57BL/6J background; 2- to 3 -month-old mice of either sex were used for the electrophysiology and biochemical experiments. The numbers of animals used are listed in the figure legends.

Live imaging. vGlut-pHluorin $(\mathrm{spH})$ was transfected (Amaxa) into hippocampal neurons prepared from P1 mouse brains at the time of plating and imaging was done $16-18 \mathrm{~d}$ in vitro (DIV). When indicated, we performed cotransfection with pCAGGS or synuclein-cherrypCAGGS.

Imaging was essentially as described previously (Mani et al., 2007). Neurons were subjected to electrical field stimulation at $20 \mathrm{~Hz}$ using a Chamlide stimulation chamber (Live Cell Instrument) and imaged at $25^{\circ} \mathrm{C}$ in Tyrode's buffer (119 mm NaCl, $2.5 \mathrm{~mm} \mathrm{KCl}, 2 \mathrm{~mm} \mathrm{CaCl}, 2 \mathrm{~mm}$ $\mathrm{MgCl}_{2}, 25 \mathrm{~mm}$ HEPES, pH 7.4, $30 \mathrm{~mm}$ glucose, $10 \mathrm{~mm}$ CNQX, and $50 \mathrm{~mm}$ APV) with or without $1 \mu \mathrm{M}$ bafilomycin A, using a Nikon Eclipse Ti-E microscope with a $60 \times$ Apo (1.49 NA) objective and an EMCCD iXon 897 (Andor Technologies) camera. For basal recordings, imaging was performed without stimulation in the absence of CNQX and APV. Images were analyzed in ImageJ (http://rsb.info.nih.gov/ij/) by placing circular ROIs on synaptic boutons that were stably in focus and responded throughout all trials. For each individual experiment 50-90 synapses were analyzed, and their fluorescence was averaged over the time. Florescence was expressed as $\Delta F / F 0$ (the difference from the initial normalized fluorescence) or as $\Delta F / F 0 / F_{\max }$ (normalized to the maximum fluorescence after the stimulation). Decay constant $(\tau)$ was calculated by fitting a single exponential decay equation using GraphPad Prism.

Cholera toxin labeling. Primary hippocampal neurons grown on coverslips were labeled with cholera toxin-HRP (CT-HRP; $10 \mu \mathrm{g} / \mathrm{ml}$ ) in Tyrode's buffer for $5 \mathrm{~min}$. Subsequently, the coverslips were (1) fixed immediately, (2) stimulated for $2 \mathrm{~min}$ by adding high $\mathrm{K}^{+}$Tyrode's buffer $(90 \mathrm{~mm} \mathrm{KCl})$ before fixing, or (3) allowed to recover poststimulation in presence of CT-HRP for 10 min before fixing. All incubations were done

(Figure legend continued.) Inset, The $100 \mathrm{AP}, 20 \mathrm{~Hz}$ stimulation trace scaled to peak fluorescence, showing that the decay kinetics is slowed in $\alpha \beta \gamma-$ Syn $^{-1-}$ neurons mice $\boldsymbol{b}, \boldsymbol{c}$, spH trace of wild-type and $\alpha \beta \gamma$-Syn ${ }^{-1-}$ neurons stimulated in the presence (purple) or absence (blue) of bafilomycin followed by $\mathrm{NH}_{4} \mathrm{Cl}$ ( $n=9$ wild-type neurons/4 experiments and $12 \alpha \beta \gamma$-Syn ${ }^{-l-}$ neurons $/ 6$ experiments). The variance in the wild-type trace is greater than $\alpha \beta \gamma$-Syn ${ }^{-1-}$ post stimulus, therefore, this portion of the trace was not analyzed further. $\boldsymbol{d}, \boldsymbol{e}, \mathrm{spH}$ responses in presence and absence of bafilomycin (bafilo) during the first $5 \mathrm{~s}$ of stimulation were subtracted to obtain endocytic rate constant (orange). $\boldsymbol{f}, \boldsymbol{g}$, The average exocytic ( $\boldsymbol{f}$ ) and endocytic (g) rate calculated from $\boldsymbol{d}$ and $\boldsymbol{e}$. $\boldsymbol{h}$, Average maximum fluorescence after exposure to $50 \mathrm{~mm}$ $\mathrm{NH}_{4} \mathrm{Cl}^{*}{ }^{*} p<0.05$. at $37^{\circ} \mathrm{C}$. Fixation was performed for $1 \mathrm{~h}$ with $1.2 \%$ glutaraldehyde in 66 mM sodium cacodylate. CT-HRP labeling was developed by incubating in $0.1 \mathrm{M}$ ammonium phosphate, $\mathrm{pH} 7.4$, containing $0.4 \mathrm{mg} / \mathrm{ml}$ diaminobenzidine and $0.005 \% \mathrm{H}_{2} \mathrm{O}_{2}$ for $15 \mathrm{~min}$. Postfixation was done for $1 \mathrm{~h}$ in $1 \% \mathrm{OsO}_{4}$ and $1 \% \mathrm{KFe}(\mathrm{CN})_{6}-0.1 \mathrm{~m}$ sodium cacodylate. Neurons were stained overnight with $2 \%$ uranyl magnesium acetate, then dehydrated in increasing ethanol concentrations, and embedded in Epon. Samples were processed for imaging by standard procedures. Pictures were captured using a Phillip CM10 transmission electron microscope. Synapses (50150) were analyzed for each condition and repeated using three independent cultures.

Hippocampal electrophysiology. Transverse hippocampal slices (400 $\mu \mathrm{m}$ thick) from 3-month-old mice were cut on a DTK-2000 microslicer (Dosaka) in ice-cold cutting solution containing the following (in $\mathrm{mm}$ ): 215 sucrose, $2.5 \mathrm{KCl}, 20$ glucose, $26 \mathrm{NaHCO}_{3}, 1.6 \mathrm{NaH}_{2} \mathrm{PO}_{4}, 1 \mathrm{CaCl}_{2}, 4$ $\mathrm{MgSO}_{4}$, and $4 \mathrm{MgCl}_{2}$. After $10 \mathrm{~min}$ of incubation at room temperature, the cutting solution was exchanged for the artificial CSF (ACSF) containing $124 \mathrm{NaCl}, 2.5 \mathrm{KCl}, 10$ glucose, $26 \mathrm{NaHCO}_{3}, 1 \mathrm{NaH}_{2} \mathrm{PO}_{4}, 2.5 \mathrm{CaCl}_{2}$, and $1.3 \mathrm{MgSO}_{4}$. Both cutting and ACSF solutions were saturated with $95 \% \mathrm{O}_{2}$ and $5 \% \mathrm{CO}_{2}, \mathrm{pH}$ 7.4. The slices recovered at room temperature for at least $1.5 \mathrm{~h}$ before recording. All experiments were performed at $25^{\circ} \mathrm{C}$. Field EPSPs (fEPSPs) were obtained by placing the recording pipette (which contained $1 \mathrm{M} \mathrm{NaCl}$ ) and the stimulating pipette (which was broken to $\sim 10 \mu \mathrm{m}$, and contained ACSF) in stratum radiatum, $\sim 200$ $\mu \mathrm{m}$ from each other and $150 \mu \mathrm{m}$ from the slice surface. Depletion/ recovery fEPSPs were obtained in the presence of $1.0 \mathrm{Mg}^{2+}$ and $4 \mathrm{~mm}$ $\mathrm{Ca}^{2+}$. Depletion and recovery plots (Fig. 4) were generated by normalizing responses to the peak amplitude of the fEPSP in the depletion train. Depletion data were best fit with a double-exponential function. Recovery data were best fit with a logarithmic function, with the equation $y=$ $(\ln ) m x+b$, from which a slope $(m)$ was generated for each slice.

Synaptic protein clustering quantification. Hippocampal neurons $14-18$ DIV were fixed using 4\% sucrose, $4 \%$ PFA in PBS, pH 7.4. Fixed neurons were permeabilized ( $1 \% \mathrm{NP} 40,0.5 \%$ BSA in PBS, $15 \mathrm{~min}$ ), then quenched in $50 \mathrm{mM} \mathrm{NH}_{4} \mathrm{Cl}$ in PBS for $15 \mathrm{~min}$ to reduce autofluorescence, and blocked in 10\% FBS, $0.5 \%$ BSA in PBS to reduce nonspecific binding. Primary and secondary antibodies were diluted in blocking buffer and incubated for $1 \mathrm{~h}$ each, at room temperature. Coverslips were washed in blocking buffer, mounted with Vectashield, and imaged by confocal microscopy, using the same parameters across genotypes. The clustering quantification was done using ImageJ as follows. First, the same threshold intensity was applied to all images and then a mask (area $1 \mu \mathrm{m}^{2}$ ) was used to quantify puncta bigger than $1 \mu \mathrm{m}^{2}$. After this processing, average fluorescence puncta size and number in control, DynKO, and $\alpha \beta \gamma$ Syn $^{-1-}$ neurons were measured.

Clathrin-coated vesicle purification. Clathrin-coated vesicles (CCVs) were purified through a biochemical fractionation of wild-type mouse brains (Maycox et al., 1992; Blondeau et al., 2004).

SV purification and proteomic analysis. SVs were purified from wildtype and $\alpha \beta \gamma-$ Syn $^{-1-}$ mice brains (Huttner et al., 1983) and subject to quantitative proteomics (iTRAQ) as described previously (Zhang et al., 2012; Westphal and Chandra, 2013). Proteins whose levels were changed ( \pm 1.5 -fold) in $\alpha \beta \gamma$-Syn ${ }^{-/-}$mice brains were considered further.

Immunoprecipitations. Wild-type and $\alpha \beta \gamma$-Syn ${ }^{-1-}$ synaptosomes were resuspended in cytosolic buffer (25 mM HEPES, pH 7.4, $125 \mathrm{~mm}$ KAc, $2.5 \mathrm{~mm} \mathrm{MgAc}, 1 \mathrm{~mm}$ DTT, and dextrose at $1 \mathrm{mg} / \mathrm{ml}$ ). For unstimulated samples, this buffer was supplemented with Phosphatase Inhibitor Cocktail 3 (Sigma) at 1:100. Samples were stimulated with $90 \mathrm{~mm} \mathrm{KCl}$ for $90 \mathrm{~s}$ at $37^{\circ} \mathrm{C}$ as indicated and then lysed with $0.5 \%$ Triton X-100. Samples were immunoprecipitated using standard procedures. Antibodies used were pre-immune serum and AP180 LP2D11 (Santa Cruz Biotechnology).

Data analysis. All analyses were done blind to genotype. Values shown are mean \pm SEM. Statistical analysis was done using GraphPad Prism. Student's two-tailed $t$ test was used to determine statistical significance ${ }^{\star} p<0.05,{ }^{* *} p<0.01$, and ${ }^{* *} p<0.001$. 

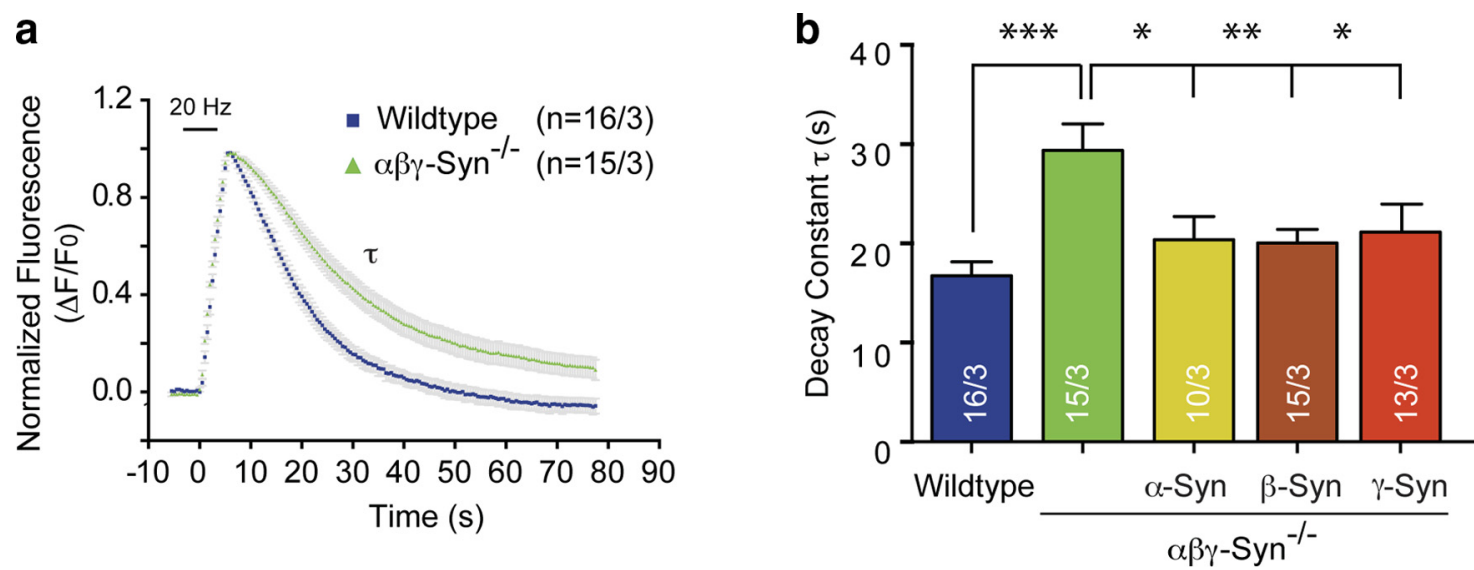

Figure 2. Mouse synucleins are functionally redundant $\boldsymbol{a}$, Average spH fluorescence normalized to the maximum fluorescence value in wild-type (blue squares) and $\alpha \beta \gamma$-Syn ${ }^{-/-}$(green triangles) neurons. ( $n=16$ wild-type and $15 \alpha \beta \gamma$-Syn ${ }^{-1-}$ neurons/3 independent experiments). $\boldsymbol{b}$, Average time constants of decay ( $\tau$ ) of spH signal after stimulation calculated for wild-type, $\alpha \beta \gamma_{\text {-Syn }}{ }^{-1-}$, and $\alpha \beta \gamma$-Syn ${ }^{-/-}$neurons transfected with mouse $\alpha$-Syn (yellow), $\beta$-Syn (brown), and $\gamma$-Syn (red). $t$ test ${ }^{* * *} p<0.001$ wild-type versus $\alpha \beta \gamma$-Syn ${ }^{-1-}$; wild-type versus synuclein rescues; $\alpha \beta \gamma$-Syn ${ }^{-1-}$ versus synuclein rescues significant ${ }^{*} p<0.05,{ }^{* *} p<0.01$.

\section{Results}

\section{Endocytic deficit in synuclein null neurons}

As synucleins are SV-associated proteins, we directly monitored the trafficking of SVs with a pHluorin reporter ( $\mathrm{spH}$; Granseth et al., 2006) in dissociated hippocampal neurons from wild-type and $\alpha \beta \gamma-$ Syn $^{-1-}$ mice. Before stimulation, the fluorescence of $\mathrm{spH}$ is quenched due to the acidic $\mathrm{pH}$ of the vesicle lumen (Granseth et al., 2006). Evoking exocytosis by electrical stimulation leads to dequenching of the $\mathrm{spH}$ signal upon exposure to the extracellular medium, followed by a decay in fluorescence due to ensuing endocytosis and re-acidification of vesicles. First, we stimulated wild-type neurons with sequential applications of 100 action potentials (APs), $300 \mathrm{AP}$, and $600 \mathrm{AP}$ at $20 \mathrm{~Hz}$ (Fig. $1 a$, blue trace). The time between stimulation was set to $2 \mathrm{~min}$ to allow wild-type neurons to return to basal levels of fluorescence. When we used the same protocol to stimulate $\alpha \beta \gamma$-Syn ${ }^{-1-}$ neurons (Fig. 1a, green trace), the time interval was not sufficient for $\alpha \beta \gamma$-Syn ${ }^{-1-}$ neurons to reach steady state. We observed slow $\mathrm{spH}$ decay that caused the second and third stimulations to start at a higher level than that for wild-type neurons. We confirmed that this is due to slower kinetics of spH decay by normalizing the peak values of the $100 \mathrm{~Hz}$ trace (Fig. $1 a$, inset). We ruled out that these changes in $\mathrm{spH}$ signal are due to altered vesicle reacidification by measuring its time course in wild-type and $\alpha \beta \gamma$ Syn $^{-1-}$ neurons upon a brief exposure to acidic medium (data not shown). We also observed that the peak fluorescence is greater in $\alpha \beta \gamma$-Syn ${ }^{-1-}$ neurons, indicating either enhanced exocytosis, impaired endocytosis, or both. Thus, even with a stimulation of $100 \mathrm{AP}(20 \mathrm{~Hz})$, we clearly observe a deficit in recycling kinetics in $\alpha \beta \gamma$-Syn ${ }^{-1-}$ neurons.

We examined if synucleins are regulating SV exocytosis, endocytosis, or both processes during this stimulation paradigm $(100 \mathrm{AP}, 20 \mathrm{~Hz})$. Since exocytosis and endocytosis occur simultaneously during repetitive stimulation, we used the vesicular $\mathrm{H}^{+}$ATPase blocker, bafilomycin, which inhibits re-acidfication of SVs (Mani et al., 2007) to separate these processes. In the presence of bafilomycin, $\mathrm{spH}$ imaging monitors exocytosis only, and the difference in fluorescence intensity in the absence and presence of bafilomycin reflects the magnitude of endocytosis during stimulation (Fig. $1 b-e$ ). Figure $1, b-c$, shows the average traces of wild-type and $\alpha \beta \gamma$-Syn ${ }^{-1-}$ neurons in the presence and absence of bafilomycin. The calculated exocytic rate constant for wild-type $(0.053 \pm 0.008 \Delta F / s)$ and $\alpha \beta \gamma$-Syn $^{-/-}(0.049 \pm 0.003$ $\Delta F / \mathrm{s}$ ) neurons were similar (Fig. $1 d-f$ ). However, the endocytic rate for $\alpha \beta \gamma$-Syn ${ }^{-1-}$ neurons was markedly decreased $(0.012 \pm$ $0.002 \Delta F /$ s for $\alpha \beta \gamma-$ Syn $^{-1-}$ vs $0.024 \pm 0.006 \Delta F /$ s for wild-type; $p<0.05$; Fig. $1 d-e, g$ ). We also measured the total SV pool size by the total fluorescence reached upon alkalizing with $\mathrm{NH}_{4} \mathrm{Cl}$ and determined they were the same for both genotypes (Fig. 1h). Thus, synucleins regulate endocytosis during repetitive activity.

Post stimulus, fast exocytosis ends but compensatory endocytosis continues until a steady state of exocytosis-endocytosis is reached, as can be seen for wild-type neurons (Fig. $2 a$, blue symbols). To compare the rate of endocytosis after stimulation, we normalized the maximum fluorescence upon stimulation. The average time constant $(\tau)$ of the poststimulus fluorescence decay in wild-type neurons was $16.8 \pm 1.4 \mathrm{~s}$, consistent with previously published results (Fig. 2a; Granseth et al., 2006; Ferguson et al., 2007; Mani et al., 2007; Kwon and Chapman, 2011; Raimondi et al., 2011). However, $\tau$ values in $\alpha \beta \gamma$-Syn ${ }^{-1-}$ neurons were significantly greater $(\tau=29.4 \pm 2.7 \mathrm{~s} ; p<0.001)$, indicating slower SV endocytosis (Fig. 2a). A direct comparison of the endocytic time constants $(\tau)$ for wild-type and $\alpha \beta \gamma$-Syn ${ }^{-1-}$ neurons is possible given the comparable fluorescence rise constant and the total SV pool size in both genotypes (Fig. $1 f, h$ ). Together, these findings indicate that endocytosis is impaired both during and after stimulation in $\alpha \beta \gamma$-Syn ${ }^{-1-}$ neurons.

Importantly, the observed defect in the rate of endocytosis was rescued by individually expressing members of the synuclein family (Fig. $2 b$; $\alpha$-Syn $\tau=20.4 \pm 2.3 \mathrm{~s}, \beta$-Syn $\tau=20.0 \pm 1.3 \mathrm{~s}$, $\gamma$-Syn $\tau=21.2 \pm 2.6 \mathrm{~s}$ ), suggesting they are functionally redundant, consistent with their high degree of sequence identity. Therefore, the synuclein protein family is needed to maintain the proper kinetics of endocytosis indicating that synucleins are regulatory endocytic proteins.

As an alternate approach to assess SV endocytosis, we labeled the plasma membrane of hippocampal neurons with CT-HRP and followed its internalization as a result of SV endocytosis by electron microscopy (Deák et al., 2004; Ferguson et al., 2007). An advantage of this approach is that it can distinguish different modes of SV endocytosis - clathrin-mediated endocytosis versus bulk endocytosis. Identification of which of these endocytic pathways are regulated by synucleins is informative to pinpoint the molecular steps regulated by these proteins. Wild-type and $\alpha \beta \gamma$ - 
a

\begin{tabular}{|c|c|c|}
\hline Rest & $\mathrm{K}^{+}$ & Recovery \\
\hline $5^{\prime}$ & 2 & $10^{\prime}$ \\
\hline
\end{tabular}

CT-HRP

b
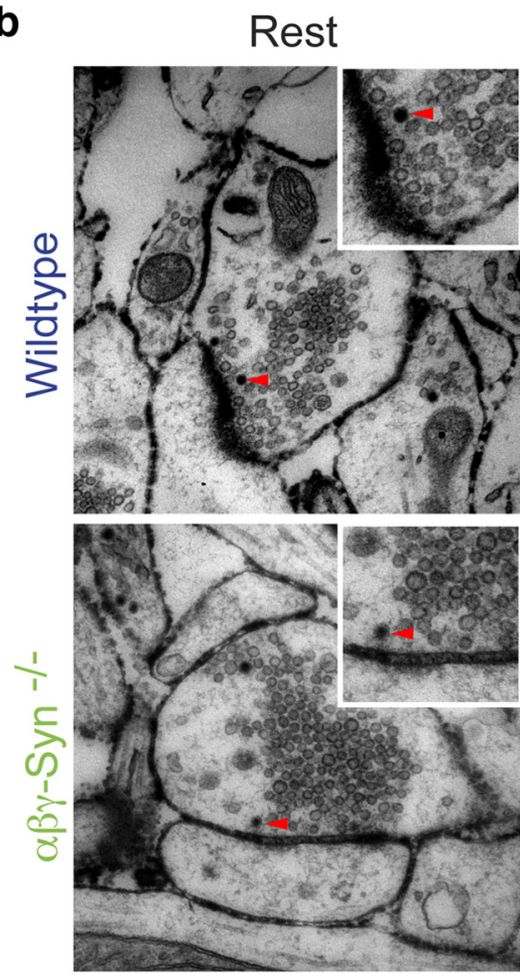

C
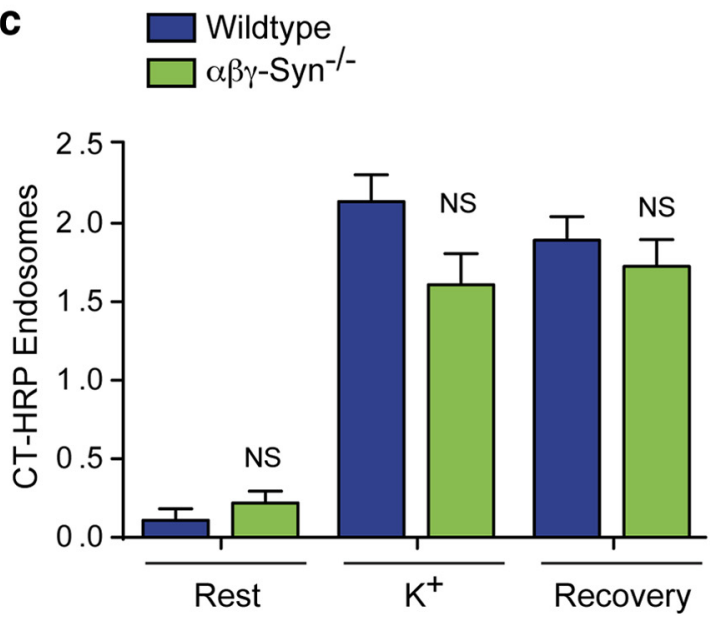

$\mathrm{K}^{+}$
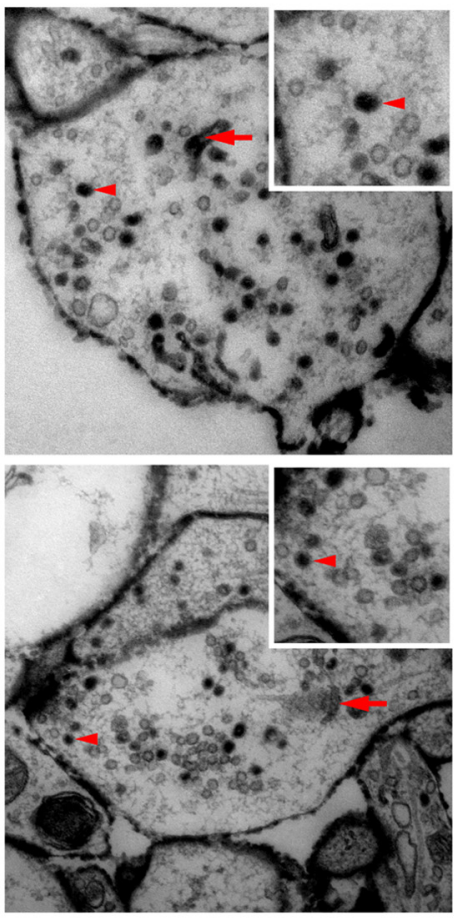

Recovery
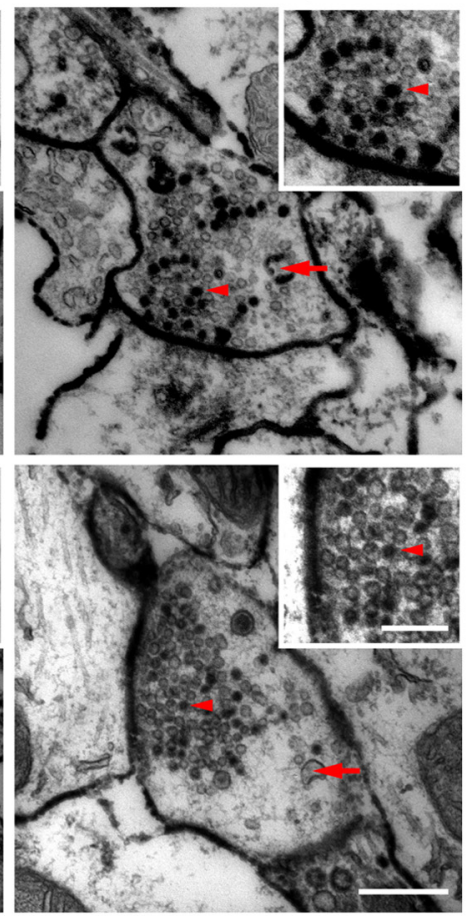

d

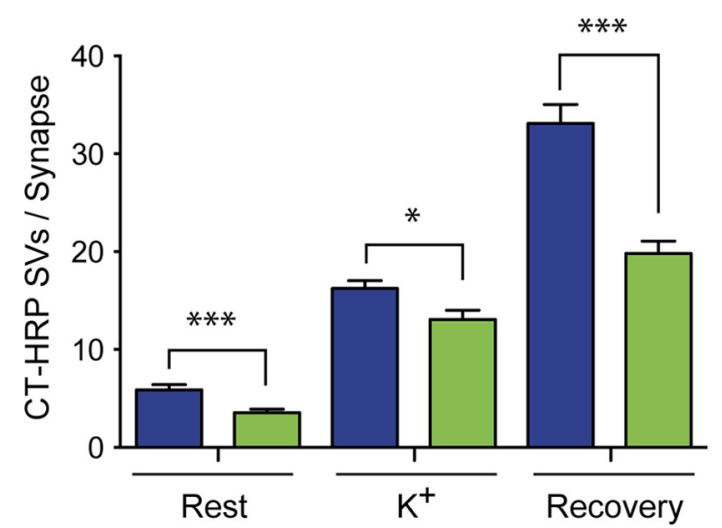

Figure 3. (T-HRP labeling reveals an endocytic deficit in $\alpha \beta \gamma$-Syn ${ }^{-1-}$ synapses. $\boldsymbol{a}, \boldsymbol{b}$, Representative electron micrographs of wild-type and $\alpha \beta \gamma$-Syn ${ }^{-1-}$ hippocampal neurons undergoing the following stimulation protocol: Tyrode's buffer for $5^{\prime}$ (Rest), $90 \mathrm{~mm} \mathrm{KCl} \mathrm{for} 2^{\prime}\left(\mathrm{K}^{+}\right)$, followed by Tyrode's buffer for 10' (Recovery) in the constant presence of (T-HRP. Red arrowhead, (T-HRP-labeled SV and red arrow, endosomes. $\boldsymbol{c}, \boldsymbol{d}$, Fraction of (T-HRP labeled (c) endosomes and (d) SVs in wild-type and $\alpha \beta \gamma^{-S y n}{ }^{-1-}$ neurons during steps of the stimulation protocol; $n=$ $125-238$ synapses (wild-type: Rest $=238, \mathrm{~K}^{+}=166$, Recovery $173 ; \alpha \beta \gamma$-Syn ${ }^{-1-}$ : Rest $=176, \mathrm{~K}^{+}=125$, Recovery $=180$ ) $/ 6$ experiments. ${ }^{*} p<0.05$, ${ }^{* * *} p<0.001$. Scale bars: $\boldsymbol{b}, 400 \mathrm{~nm}$; $\boldsymbol{b}$, inset, $200 \mathrm{~nm}$.

Syn ${ }^{-1-}$ hippocampal cultures were treated with CT-HRP and subjected to the denoted stimulation and recovery protocol (Fig. $3 a, b)$. First, we quantified the number of labeled endosomes as a measure of bulk endocytosis and found no significant difference (Fig. $3 c$ ), suggesting that synucleins only affect clathrin-mediated endocytosis, which has been validated as the physiologically relevant mode of retrieval in hippocampal synapses (Granseth et al., 2006; Balaji and Ryan, 2007). Ultrastructural quantification con- firmed that $\alpha \beta \gamma$-Syn ${ }^{-1-}$ synapses have fewer CT-HRP-labeled SVs than wild-type synapses, both during $(23.4 \% ; p<0.05)$ and after stimulation ( $41.8 \% ; p<0.001$; Fig. $3 d)$, consistent with the spH imaging data (Figs. 1, 2). $\alpha \beta \gamma$-Syn ${ }^{-1-}$ synapses also show a modest, albeit significant, decrease in labeled SVs at rest (wildtype $5.9 \pm 0.5$ vs $\alpha \beta \gamma-S_{y n}{ }^{-\prime-} 3.5 \pm 0.35$; Fig. $3 d$ ). Analyses of mouse mutants for well established endocytic proteins also show a similar decrease in CT-HRP-labeled vesicles both at rest and 
a
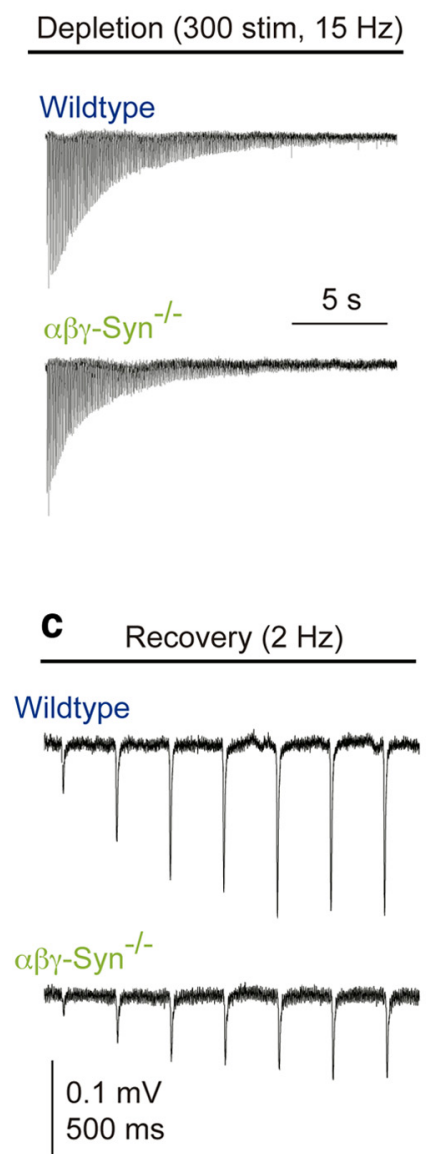

b

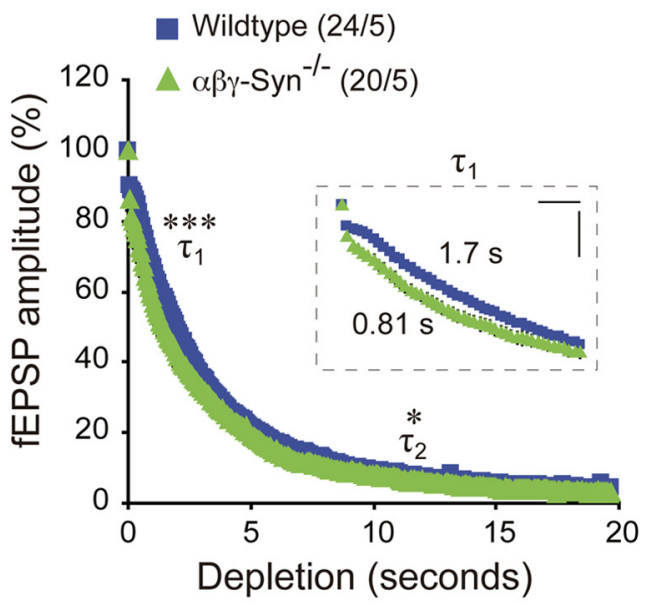

d

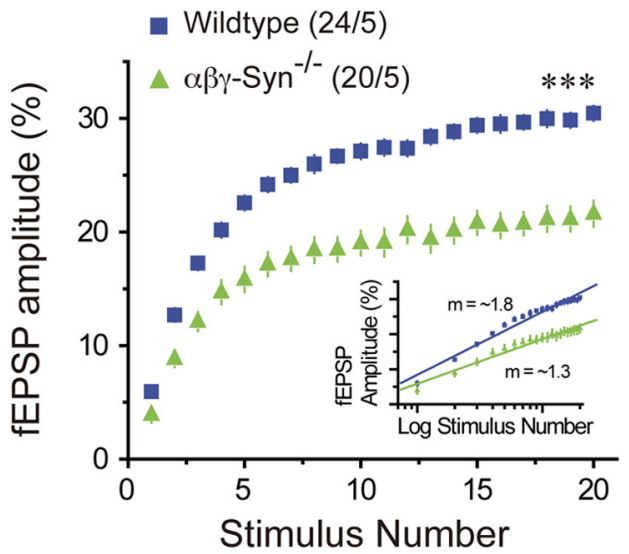

Figure 4. Impaired synaptic depletion and recovery in synuclein null brains. $\boldsymbol{a}$, Representative synaptic responses generated by repetitive trains ( 300 stimuli, $15 \mathrm{~Hz}$ ) in wild-type and $\alpha \beta \gamma$-Syn ${ }^{-1-}$ mice. Traces are averages of individual animals $(n=24 / 5$ wild-type and 20/5 $\alpha \beta \gamma$-Syn ${ }^{-1-}$ slices/animal). $\boldsymbol{b}$, Summary data showing amplitudes of fEPSPs in depletion train. Responses from each slice were normalized to the peak fEPSP amplitude in the train. Inset calibration: $20 \%$ of fEPSP amplitude, 500 ms. $\boldsymbol{C}$, Individual fEPSPs immediately after the depletion train showed impaired recovery in $\alpha \beta \gamma$-Syn ${ }^{-1-}$ slices. The recovery paradigm was initiated $250 \mathrm{~ms}$ following the depletion train. Traces are averages of individual animals (4 slices/animal). $\boldsymbol{d}$, Summary of synaptic recovery in wild-type and $\alpha \beta \gamma$-Syn ${ }^{-1-}$ mice. Responses from each slice were normalized to the first fEPSP in the depletion train. Inset, Slope values represent percentage baseline recovered per stimulus number. Note slower recovery rate in $\alpha \beta \gamma_{\text {-Syn }}{ }^{-/-}$slices.

upon stimulation (Ferguson et al., 2007; Milosevic et al., 2011), reinforcing the notion that synucleins share a similar function. We conclude that synucleins are required for efficient clathrinmediated SV endocytosis during as well as after synaptic activity. This agrees with data from cell lines where $\alpha$-synuclein was shown to promote receptor-mediated endocytosis, for example, of the transferrin receptor (Ben Gedalya et al., 2009; Cheng et al., 2011; Kisos et al., 2014), a process which shares the same regulatory proteins and basic mechanisms of SV endocytosis.

\section{Electrophysiological properties of synuclein null brains}

What is the physiological significance of the endocytic defects in $\alpha \beta \gamma$-Syn ${ }^{-1-}$ neurons? To answer this question, we first evaluated the ability of wild-type and $\alpha \beta \gamma$-Syn ${ }^{-1-}$ neurons to maintain neurotransmitter release upon sustained presynaptic activity (Chandra et al., 2004; Greten-Harrison et al., 2010). In acute hippocampal slices, Schaffer collateral-CA1 synapses were activated with a 300 pulse train ( $15 \mathrm{~Hz}$; see Materials and Methods), resulting in nominally complete depression of synaptic transmission, a phenomenon likely due to depletion of SVs (Fig. $4 a$ ). Both the initial and secondary rates of depletion were faster in $\alpha \beta \gamma$-Syn ${ }^{-1-}$ than in wild-type mice $\left(\tau_{1}=0.81 \pm 0.17\right.$ vs $1.7 \pm$ $0.15 \mathrm{~s} ; p<0.001 ; \tau_{2}=3.9 \pm 0.3$ v $5.8 \pm$ 0.7 s; $p<0.05$; Fig. $4 a, b)$. This effect was small but significant, consistent with our observations that deletion of synucleins does not completely block SV endocytosis, but slows the process. To test whether $\alpha \beta \gamma$-Syn ${ }^{-1-}$ neurons also show deficits in recovery, the depletion train was immediately followed by a 20 pulse $(2 \mathrm{~Hz})$ stimulation paradigm. Here we observed that the initial rate of return toward baseline was slower in $\alpha \beta \gamma$-Syn ${ }^{-1-}$ than wild-type mice (wild-type, $1.8 \pm 0.06, \alpha \beta \gamma-$ Syn $^{-l-}$, $1.3 \pm 0.04 ; p<0.0001$; Fig. $4 c, d)$. The time constant of the recovery phase was in $\alpha \beta \gamma$-Syn ${ }^{-1-}$ than in wild-type mice $(6.3 \pm 0.9$ s vs $1.8 \pm 0.06 \mathrm{~s} ; p<0.0001$; Fig. $4 c, d)$. Thus, as previously reported for loss-of-function mutants of endophilin, dynamin, and synaptojanin (Cremona et al., 1999; Ferguson et al., 2007; Mani et al., 2007; Milosevic et al., 2011), loss of synucleins also slows down recovery from depletion. It is noteworthy that synuclein single knock-outs (KOs) do not exhibit synaptic depression or impaired recovery (Chandra et al., 2004), supporting the conclusion that synucleins are functionally redundant and compensate for each other in SV endocytosis

\section{Comparison of $\boldsymbol{\alpha} \boldsymbol{\beta} \boldsymbol{\gamma}$-Syn KO and dynamin 1, 3 KO synapses}

Clathrin-mediated SV endocytosis is temporally organized into distinct stepscargo recruitment by endocytic adaptors, membrane bending, bud invagination, bud neck scission by dynamins to generate a free CCV, and uncoating to release a nascent SV (Dittman and Ryan, 2009; Saheki and De Camilli, 2012). The sequential recruitment of endocytic proteins allows for vectorial occurrence of these reactions. Dynamin 1, 3 KO (DynDKO) synapses are arrested at the fission step and accumulate clathrin pits, many on tree-like membrane invaginations (Ferguson et al., 2007; Raimondi et al., 2011). These are detectable by immunofluorescence as clusters of endocytic proteins (Fig. 5a). To determine whether $\alpha$-synuclein behaves similar to well characterized endocytic proteins, we immunostained control and DynDKO neurons for $\alpha$-synuclein and clathrin. In control neurons, $\alpha$-synuclein is enriched at synapses and has a punctate appearance, while clathrin is dispersed (Fig. $5 a$ ). In DynDKO neurons, $\alpha$-synuclein puncta colocalize with clathrin (Fig. $5 a$ ) and the $\alpha$-synuclein puncta size increases similar to those of clathrin (Fig. $5 b$ ). This is in marked contrast to other peripherally associated SV proteins such as Rab3a and synapsin, which are dispersed in DynDKO synapses due to sequestration of SV membranes in endocytic intermediates (Raimondi et al., 2011). These immunocytochemistry results affirm that $\alpha$-synuclein behaves like an endocytic protein and is likely to act before action of dynamins. 
a

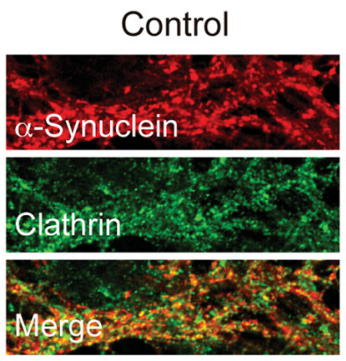

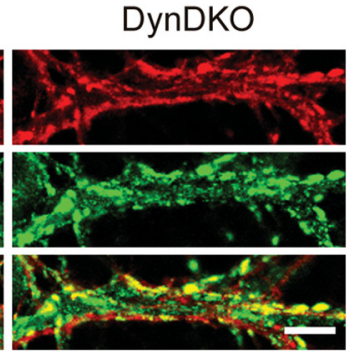

b

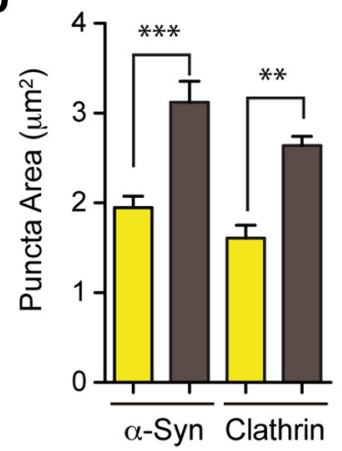

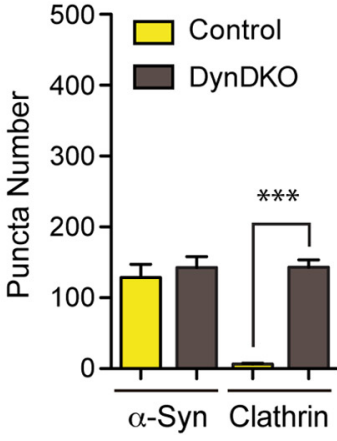

C

Control

DynDKO
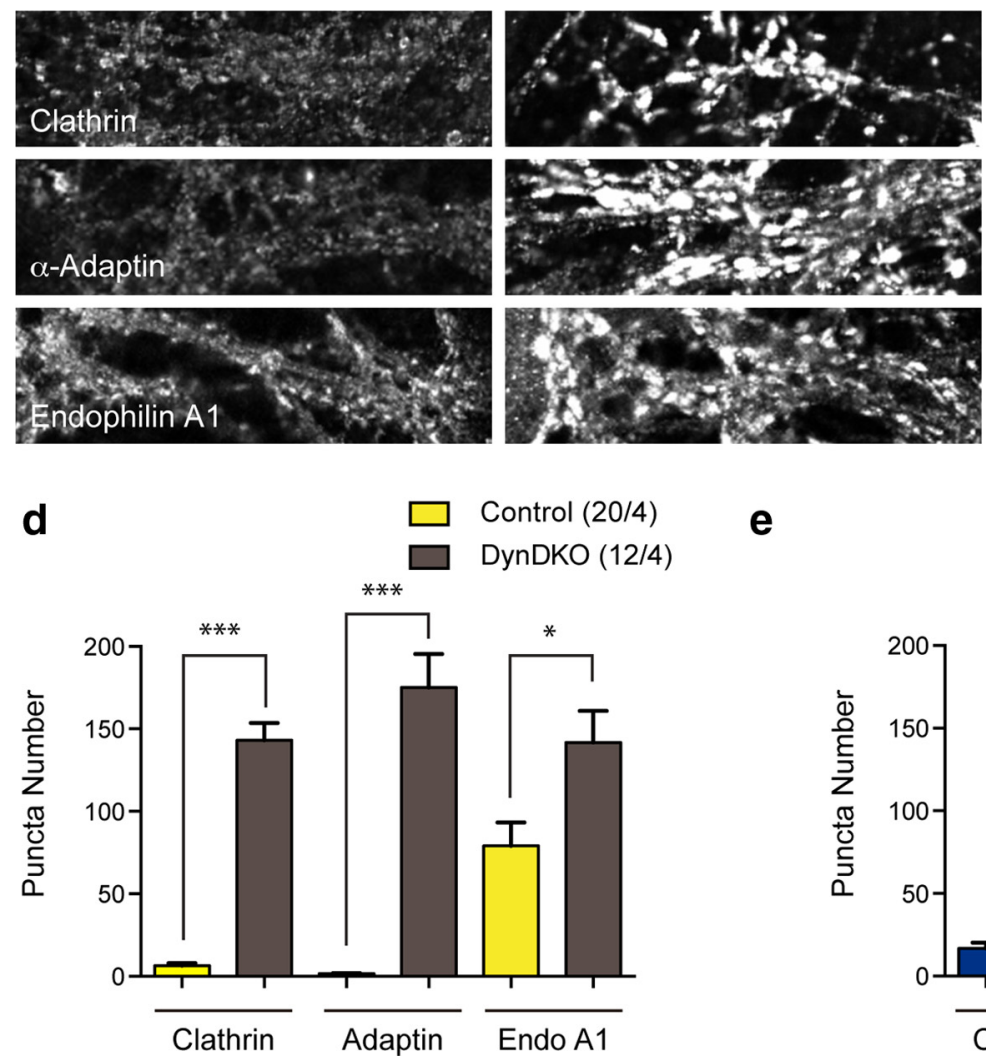

e
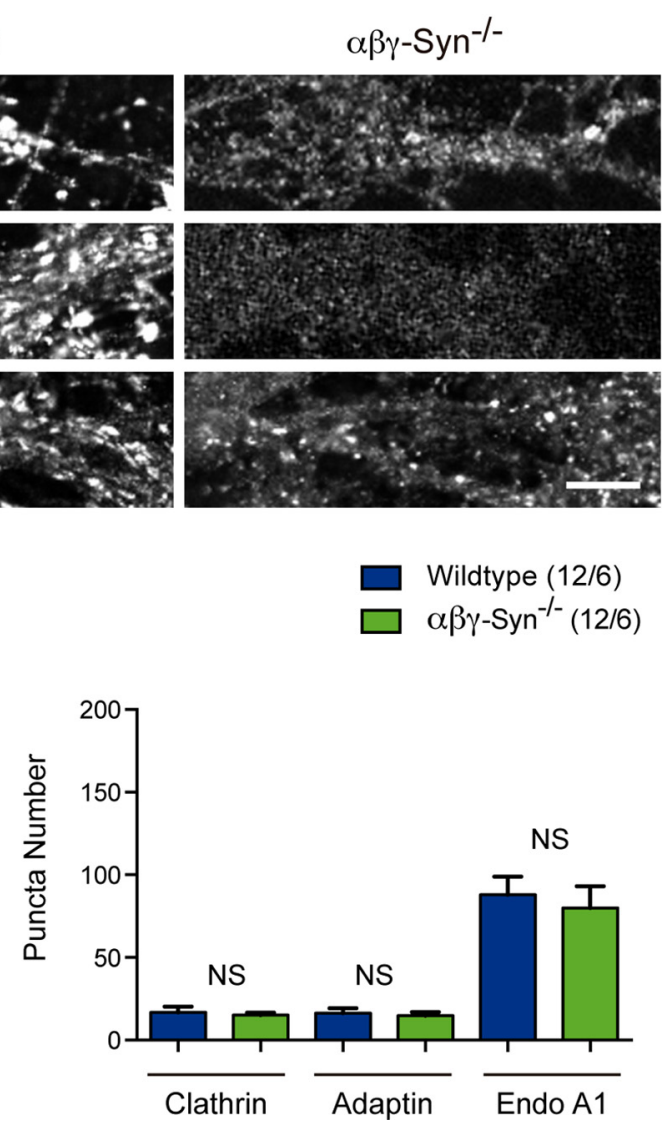

Figure 5. Synucleins act prior to the action of dynamins. $\boldsymbol{a}, \boldsymbol{b}$, Colocalization of $\alpha$-synuclein and clathrin in DynK0 neurons. $\boldsymbol{a}$, Representative images and ( $\boldsymbol{b})$ quantification of $\alpha$-synuclein and clathrin fluorescence puncta size and number $\left(>1 \mu \mathrm{m}^{2}\right)$ in control and DynK0 neurons. Scale bar: $\boldsymbol{a}, 7 \mu \mathrm{m}$. c, Representative immunofluorescence images of clathrin, $\alpha$-adaptin, and endophilin A1 in Control, DynDK0, and $\alpha \beta \gamma$-Syn ${ }^{-1-}$ neurons. Scale bar, $7 \mu \mathrm{m}$. d, $\boldsymbol{e}$, Quantification of clathrin, $\alpha$-adaptin, and endophilin A1 fluorescence puncta $\left(>1 \mu \mathrm{m}^{2}\right)$ in control and DynDKO neurons (d), and in wild-type and $\alpha \beta \gamma$-Syn ${ }^{-1-}$ neurons (e) DynDK0; $n=12-20$ images/4 experiments, except for endophilin A1 $n=6-16$ images $/ 2$ experiments. $\alpha \beta \gamma-$-Syn ${ }^{-1-} 12$ images $/ 6$ experiments.

Next we examined the accumulation of endocytic proteins in wild-type, $\alpha \beta \gamma-\mathrm{Syn}^{-1-}$, and DynDKO neurons (Raimondi, 2011) by light and electron microscopy. Unlike in DynDKO, there was no discernible change in the pattern of endocytic proteins tested in $\alpha \beta \gamma-\mathrm{Syn}^{-1-}$ neurons (Fig. $5 c-e$ ). This is in line with our findings that endocytosis is slowed $\alpha \beta \gamma-\mathrm{Syn}^{-1-}$ neurons but not blocked like in DynDKO neurons. We also studied wild-type and $\alpha \beta \gamma$-Syn ${ }^{-1-}$ synapses by electron microscopy and quantitated the number of CCVs at rest, after stimulation and recovery (Fig. 6a,b). The CCV number between wild-type and $\alpha \beta \gamma-\mathrm{Syn}^{-1-}$ were similar, under the three conditions, with a tendency for increased CCVs in $\alpha \beta \gamma$-Syn ${ }^{-/-}$synapses upon $\mathrm{KCl}$ stimulation. Regardless, there were 100 -fold fewer CCVs in $\alpha \beta \gamma$ $\mathrm{Syn}^{-1-}$ than reported in the literature for DynDKO neurons and clathrin pits studded on tree-like invaginations were absent in $\alpha \beta \gamma$-Syn ${ }^{-1-}$ synapses (Fig. 6a,b; Ferguson et al., 2007; Raimondi et al., 2011). Thus $\alpha \beta \gamma-$ Syn $^{-l-}$ synapses do not phenocopy the ultrastructure of DynDKO synapses, but are similar to KOs of early endocytic proteins such as amphiphysin (Di Paolo et al., 2002).

$\mathrm{PI}(4,5) \mathrm{P}_{2}$ levels are dramatically altered in late stage CCV uncoating mutants (Cremona et al., 1999; Yim et al., 2010). We measured PI $(4,5) \mathrm{P}_{2}$ levels in wild-type and $\alpha \beta \gamma$-Syn ${ }^{-1-}$ synapses and found no differences between the two genotypes (Fig. $6 e$ ), affirming that synucleins do not act at late stages of SV endocytosis. Furthermore, biochemical purification of CCVs revealed that synucleins are not enriched in this fraction (Fig. $6 c, d)$.Taken together, synucleins are likely to act before dynamin. 
a

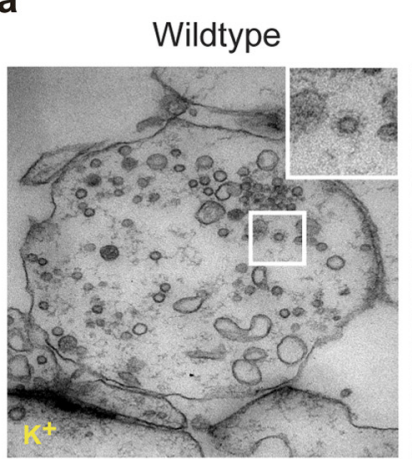

C

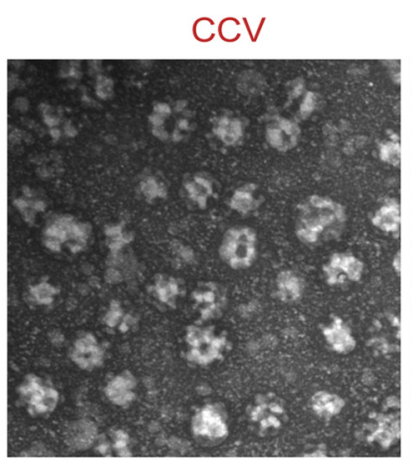

b
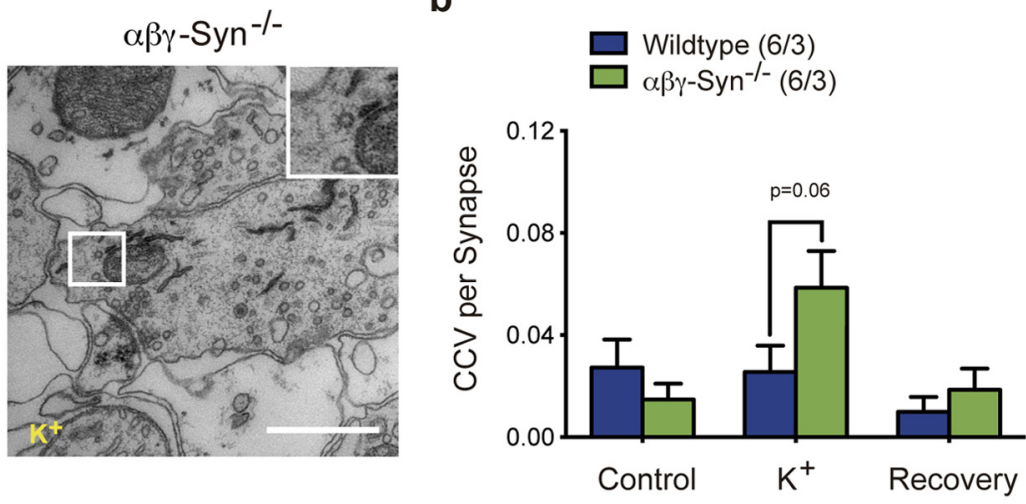

d

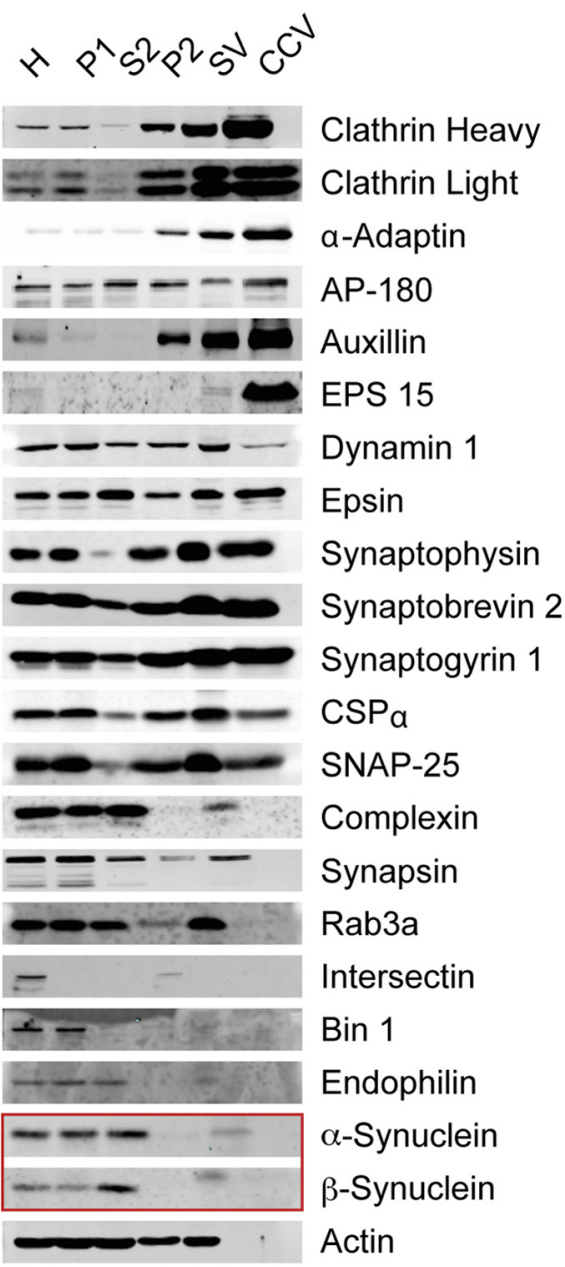

Figure 6. Lack of enrichment of CCVs in $\alpha \beta \gamma-$ Syn $^{-1-}$ synapses. $\boldsymbol{a}$, Representative electron microscopic images used for quantification of CCVs in wild-type and $\alpha \beta \gamma$-Syn ${ }^{-1-}$ synapses. Electron microscopic images showing CCVs in wild-type and $\alpha \beta \gamma$-Syn ${ }^{-I-}$ synapses after high KCI stimulation. Scale bars: $400 \mathrm{~nm}$; inset, $200 \mathrm{~nm}$. $\boldsymbol{b}$, CCV number in wild-type (blue) and $\alpha \beta \gamma$-Syn ${ }^{-1-}$ (green) at rest, after 90 s of $90 \mathrm{~mm} \mathrm{KCl} \mathrm{stimulation,} \mathrm{and} 10$ min of subsequent recovery. CCV numbers in $\alpha \beta \gamma$-Syn ${ }^{-1-}$ are not significantly different from wild-type, though there is a tendency for increased CCV upon KCl stimulation; $n=6$ coverslips/3 experiments; $50-100$ synapses each condition. $c$, Electron microscopic images of CCV and SVs derived from a biochemical fractionation of wild-type brains (Maycox et al., 1992), confirming the high purity of these fractions. $\boldsymbol{d}$, Subcellular fractionation of wild-type brains showing the initial homogenate (H), postnuclear pellet (P1), cytosol (S2), crude synaptosomes (P2), SVs, and CCVs. Immunodetection of CCV components, SV proteins, and endocytic and exocytic proteins as well as $\alpha$ - and $\beta$-synuclein. The enrichment of integral CCV proteins and replication of known fractionation patterns for other synaptic proteins corroborates the success of the fractionation. Similar results were obtained in threeindependent experiments. $\boldsymbol{e}$, Total acidic brain lipids were extracted and quantified as described by Volpicelli-Daley et al. (2010). PI(4)P and PI(4,5) $\mathrm{P}_{2}$ amounts were normalized to the total amount of lipids. The levels of all phosphoinositides are similar in wild-type (blue bars) and synuclein null ( $\alpha \beta \gamma^{-S y n}{ }^{-1-}$; green bars) brains; $n=6$ brains/genotype.

Biochemical analysis of endocytic function of synucleins To obtain a biochemical understanding of how synucleins could participate in SV endocytosis, we examined the levels of prominent exocytic and endocytic proteins in synaptosomes derived from wild-type and $\alpha \beta \gamma$-Syn ${ }^{-1-}$ brains (Fig. $6 c$ ). We did not see any changes for the exocytic proteins tested, similar to our published results for total brain proteins (Greten-Harrison et al., 2010). However, we observed increased levels for the heavy and 
a

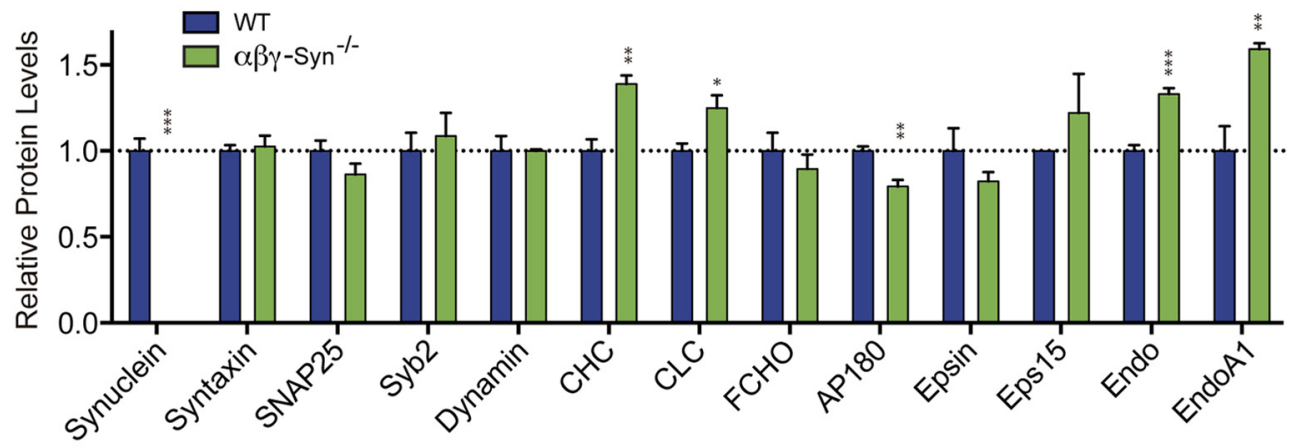

b

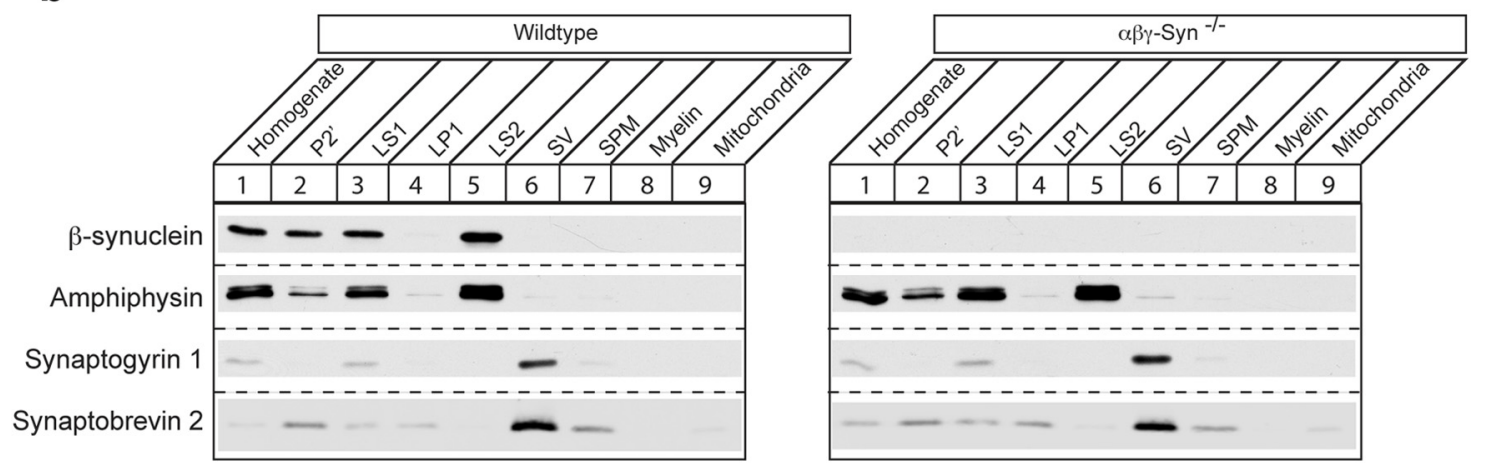

C

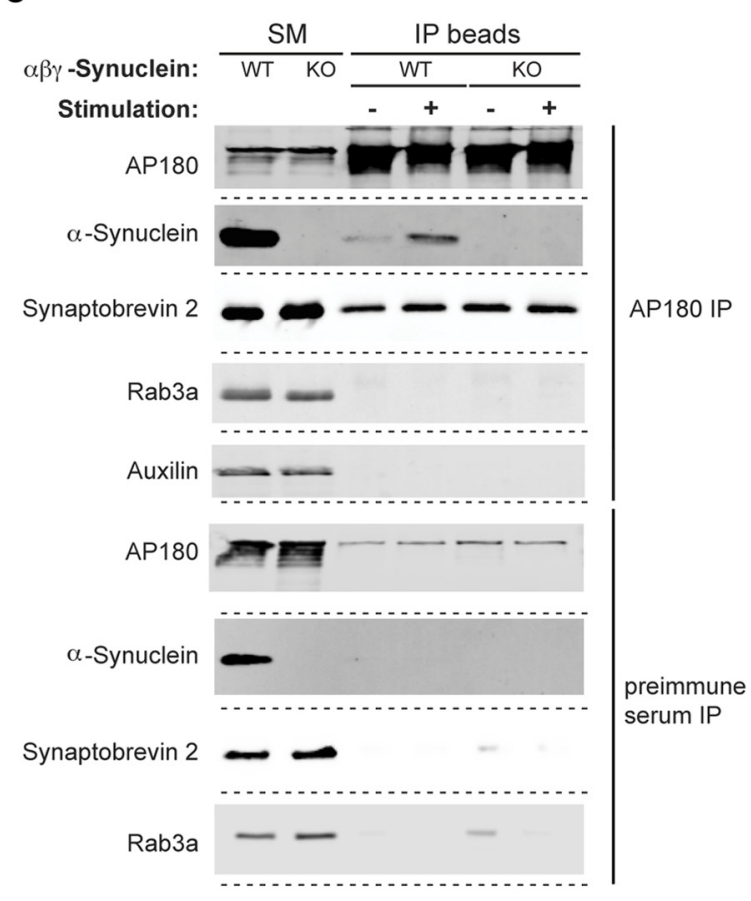

d
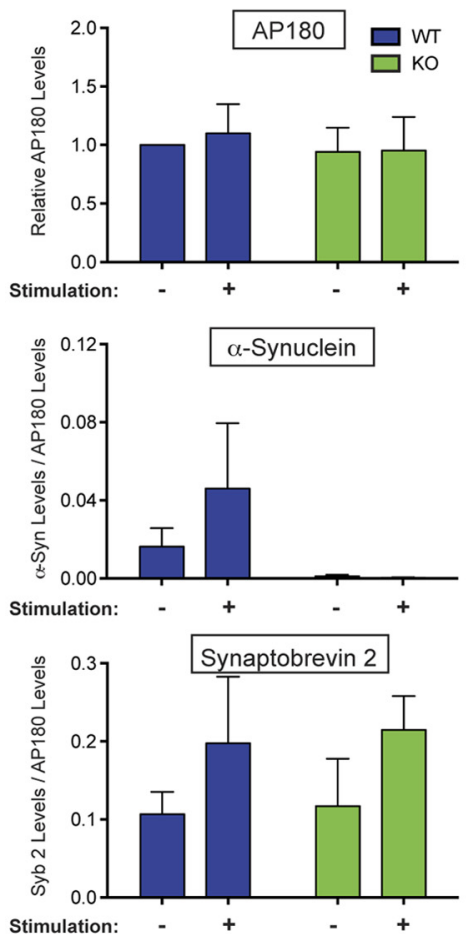

Figure 7. Synucleins act at early steps in SV endocytosis. $\boldsymbol{a}$, Quantification of presynaptic proteins in synaptosomes isolated from wild-type and $\alpha \beta \gamma$-Syn ${ }^{-1-}$ brains. $\boldsymbol{b}$, Subcellular fractionation of wild-type and $\alpha \beta \gamma$-Syn ${ }^{-1-}$ brains showing initial homogenate (H), crude synaptosomes (P2'), fractions LS1 and LP1 en route to purify synaptic cytosol LS2, SVs, and synaptic plasma membrane (SPM), myelin, and mitochondria. Immunoblotting of amphiphysin as a synaptic cytosolic protein and synaptogyrin 1 as a SV protein to confirm purity of fractions. Purified SVs were subject to iTRAQ analysis ( $n=3$ independent experiments), and synaptobrevin 2 levels were found to be decreased in $\alpha \beta \gamma$-Syn ${ }^{-1-}$ SVs and confirmed by quantitative immunoblotting. c, Immunoprecipitations using AP180 and pre-immune serum from wild-type (WT) and $\alpha \beta \gamma$-Syn ${ }^{-I-}$ (K0) synaptosomes without ( - ) or by KCl stimulation (+).d, Quantification of immunoblots such as shown in c. From three independent experiments. 


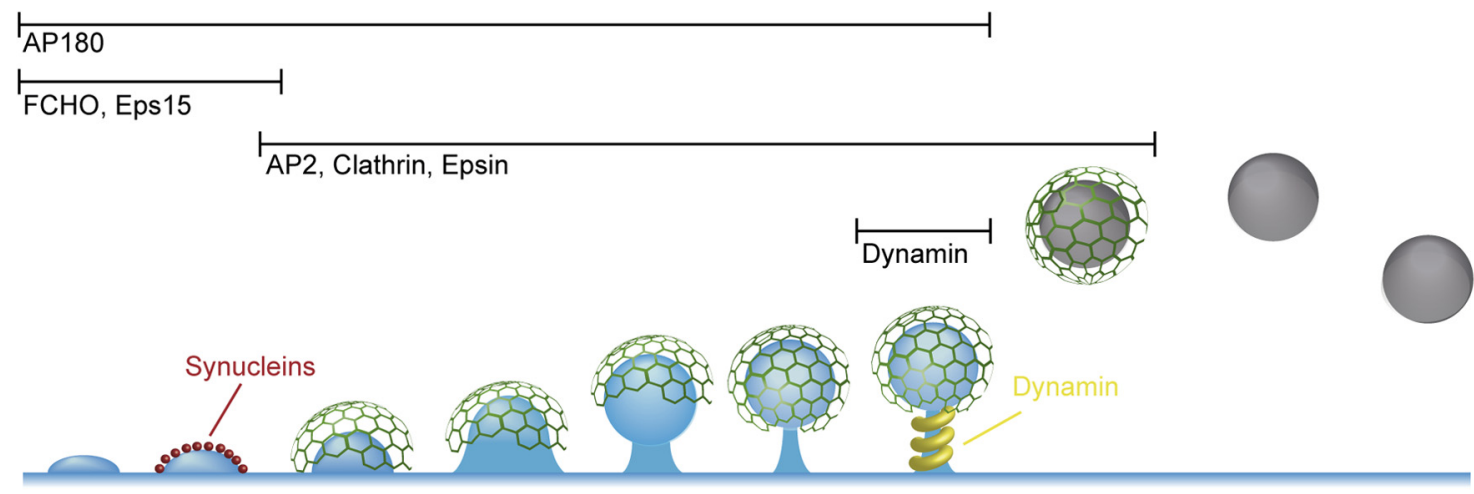

Figure 8. Model of synucleins function during SV endocytosis. Based on our results, we propose that synucleins act during early steps on SV endocytosis, which involve membrane bending and cargo selection. Horizontal lines indicate duration of action of the given endocytic protein. The blue color denotes $\mathrm{PI}(4,5) \mathrm{P}_{2}$ levels.

light chains of clathrin and endophilins. The select increase in endophilins, but not FCHO, is consistent with our previous proteomic analysis of these mice (Westphal and Chandra, 2013). The increased levels of clathrin and endophilins may be compensatory for the slow endocytic rate in $\alpha \beta \gamma$-Syn ${ }^{-1-}$. Intriguingly, we also observed decreased levels of AP180, a neuronal endocytic adaptor for the v-SNARE synaptobrevin 2 (Koo et al., 2011). AP180 was previously identified, along with AP2, as modifiers of $\alpha$-synuclein function in an unbiased RNAi screen in Caenorhabditis elegans (Kuwahara et al., 2008).

As AP180 acts early in SV endocytosis before the action of dynamins, our quantitative immunoblotting results prompted us to test if AP180 binds synucleins (Fig. $6 d, e$ ). We performed immunoprecipitations from wild-type and $\alpha \beta \gamma$-Syn ${ }^{-/-}$synaptosomes at rest or after high $\mathrm{K}^{+}$stimulation to increase endocytosis. We observed that AP180 interacts with $\alpha$-synuclein weakly at rest and that binding was promoted by stimulation (Fig. $6 d, e)$. This interaction was not direct, as recombinantly purified AP180 and $\alpha$-synucleins did not bind each other (data not shown). Therefore, we tested if this interaction is mediated by synaptobrevin 2, which has been shown to bind both proteins (Burré et al., 2010; Koo et al., 2011). Interestingly, AP180, synaptobrevin 2 and $\alpha$-synuclein can be immunoprecipitated together (Fig. $6 d$ ). The binding of synaptobrevin 2 to AP180 was independent of its interaction with $\alpha$-synuclein, consistent with earlier studies that showed distinct regions on synaptobrevin 2 bind AP180 (31-68 aa of Syb2; (Koo et al., 2011) and $\alpha$-synuclein (1-29 aa of Syb2; Burré et al., 2010). We next tested if sorting of synaptobrevin 2 is altered in $\alpha \beta \gamma$-Syn ${ }^{-/-}$synapses. Wildtype and $\alpha \beta \gamma$-Syn ${ }^{-/-}$brains were fractionated to purify SVs (Fig. $7 b$ ), and the SV proteomes were compared using unbiased quantitative proteomics (Westphal and Chandra, 2013). We observed that synaptobrevin 2 was significantly decreased in $\alpha \beta \gamma$-Syn ${ }^{-1-}$ SVs (Fig. $7 b ; \alpha \beta \gamma$-Syn ${ }^{-1-}=0.67 \pm 0.05$; wild-type $=1.00 ; p<0.05, n=3$ experiments), though overall levels in synapses were unchanged (Fig. 7a). Altogether, these biochemical experiments suggest that synucleins may act transiently in membrane bending and cargo selection steps of SV endocytosis (Fig. 8).

\section{Discussion}

In this study, we directly demonstrate that synucleins are required for rapid and efficient clathrin-mediated SV endocytosis at the presynaptic terminal. $\alpha \beta \gamma-S_{-1}{ }^{-1-}$ neurons showed defective SV endocytosis both during and after neuronal activity (Figs. $1-3)$. The slower endocytosis observed in $\alpha \beta \gamma-$ Syn $^{-/-}$neurons could be rescued by individually expressing $\alpha$-, $\beta$-, or $\gamma$-synuclein (Fig. 2b), underscoring that regulation of SV endocytosis is a conserved function of the synuclein protein family. The endocytic deficits of $\alpha \beta \gamma$-Syn ${ }^{-/-}$neurons have marked physiological consequences, which result in faster synaptic depression and a slow recovery of neurotransmission (Fig. 4). $\alpha$-Synuclein localizes to endocytic clusters observed in DynDKO neurons (Ferguson et al., 2007; Raimondi et al., 2011; Fig. 5a), suggesting that synucleins act temporally before dynamins. Our biochemical experiments support this interpretation (Fig. 6) and indicate that synucleins act transiently to regulate the assembly of the synaptic endocytic machinery.

\section{Biochemical and genetic interactions support an endocytic function for synucleins}

The biochemical properties and interactions of synucleins are well suited to fulfill an early endocytic function. Synucleins, via their conserved $\mathrm{N}$ termini, bind acidic lipids, in particular $\mathrm{PI}(4,5) \mathrm{P}_{2}$ (Narayanan and Scarlata, 2001), a property shared by many endocytic proteins (Di Paolo et al., 2002; Milosevic et al., 2011). Significantly, synucleins can sense/generate membrane curvature (Jensen et al., 2011; Westphal and Chandra, 2013) and the width of the membrane tubules generated by synucleins is consistent with the neck of clathrin-coated buds (Westphal and Chandra, 2013). Consequently synucleins, through their interactions with acidic lipids and AP180 (Fig. 7c,d), may be involved in coordination of membrane bending to initiate SV endocytosis. Previous studies on $\alpha$-synuclein protein interactions also corroborate an endocytic role. In searches for potential $\alpha$-synuclein interactors, binding to several early acting endocytic proteins have been reported. AP-2, AP-1, and clathrin were pulled down with a C-terminal construct of $\alpha$-synuclein (Li et al., 2002) and clathrin was also pulled down with full-length $\alpha$-synuclein (Jin et al., 2007). However, many additional synuclein protein interactors have been identified in different systems (Payton et al., 2001; Woods et al., 2007).

The genetic interactions of synucleins are also consistent with an endocytic function for synucleins. Transgenic overexpression of $\alpha$-synuclein completely rescues the neurodegeneration and early lethality of $\operatorname{CSP} \alpha \mathrm{KO}$, while deletion of synucleins exacerbates these phenotypes (Chandra et al., 2005). CSP $\alpha$ is a presynaptic co-chaperone for $\mathrm{Hsc} 70$. The $\mathrm{CSP} \alpha / \mathrm{Hsc} 70$ complex acts on SNAP-25 and dynamin 1 to facilitate the SV cycle (Sharma et al., 2011; Zhang et al., 2012), and $\operatorname{CSP} \alpha \mathrm{KO}$ neurons show both impaired SV exocytosis and endocytosis (Rozas et al., 2012). The $\operatorname{CSP} \alpha \mathrm{KO} / \alpha$-synuclein crosses indicate that $\alpha$-synuclein is likely 
to act in either a SNAP-25-related (exocytic) or dynamin 1 (endocytic)-related pathway. The endocytic phenotypes of $\alpha \beta \gamma$ Syn $^{-1-}$ neurons are congruent with the fact that $\operatorname{CSP} \alpha$ regulates SV endocytosis via dynamin (Zhang et al., 2012). As previously noted, further support of an endocytic function for synucleins comes from a genetic modifier screen for $\alpha$-synuclein function in C. elegans, which identified that SV endocytosis is the main pathway impacted and modifiers included AP180 and AP2 (Kuwahara et al., 2008).

\section{Does $\alpha$-synuclein work in SV endocytosis only?}

While our data strongly suggest that synucleins are regulatory endocytic proteins, they do not rule out a role of synucleins in SV exocytosis. Deletion of synucleins does improve basal neurotransmission in young mice (Greten-Harrison et al., 2010; Anwar et al., 2011). Conversely, overexpression of $\alpha$-synuclein across many systems consistently decreased neurotransmission (Larsen et al., 2006; Nemani et al., 2010). Therefore it is possible that $\alpha$-synuclein works in both exocytosis and endocytosis. Paradoxically, the increase in basal synaptic transmission in $\alpha \beta \gamma$ Syn ${ }^{-1-}$ mice was not accompanied by an increase in release probability (Greten-Harrison et al., 2010). Based on these previous and present findings, we hypothesize two possible scenarios after considering the pathological and physiological functions of synucleins: (1) toxic $\alpha$-synuclein oligomers (in both wild-type and transgenic overexpression) inhibit SNARE complex formation (Choi et al., 2013) and thus SV exocytosis, while native synucleins function in the endocytic arm of the SV cycle to facilitate endocytosis and (2) native synucleins, through their membrane bending properties and AP180/synaptobrevin 2 binding, are involved in exo-endo coupling. Both of these scenarios are consistent with the fact the genetic interaction of $\alpha$-synuclein with $\operatorname{CSP} \alpha$, as $\operatorname{CSP} \alpha$ binds both SNAP-25 and dynamin and facilitates exo-endo coupling. The findings that VAMP/synaptobrevin 2 is essential for fast synaptic-vesicle endocytosis (Deák et al., 2004) and that AP180 is an endocytic adaptor for sorting of SNAREs (Koo et al., 2011) also support these hypotheses. Further detailed genetic and biochemical experiments are needed to distinguish between these possibilities. Regardless, these data point to synucleins acting at the earliest steps of the endocytic process.

\section{Endocytic pathway and PD}

Our findings categorize $\alpha$-synuclein with other familial PD genes such as LRRK2 (Matta et al., 2012) and Parkin (Trempe et al., 2009), which regulate SV endocytosis. Recently, mutations in endocytic proteins such as auxilin (Edvardson et al., 2012), synaptojanin (Krebs et al., 2013), and sequence variants in GAK (Nalls et al., 2011; Lill et al., 2012) have been linked to PD. Collectively, these results strongly implicate the SV endocytic pathway in the etiology of PD. Finally, as all members of the synuclein family are functionally redundant for SV endocytosis, selective lowering of $\alpha$-synuclein levels may be a suitable therapeutic approach for PD.

\section{References}

Anwar S, Peters O, Millership S, Ninkina N, Doig N, Connor-Robson N, Threlfell S, Kooner G, Deacon RM, Bannerman DM, Bolam JP, Chandra SS, Cragg SJ, Wade-Martins R, Buchman VL (2011) Functional alterations to the nigrostriatal system in mice lacking all three members of the synuclein family. J Neurosci 31:7264-7274. CrossRef Medline

Balaji J, Ryan TA (2007) Single-vesicle imaging reveals that synaptic vesicle exocytosis and endocytosis are coupled by a single stochastic mode. Proc Natl Acad Sci U S A 104:20576-20581. CrossRef Medline
Ben Gedalya T, Loeb V, Israeli E, Altschuler Y, Selkoe DJ, Sharon R (2009) Alpha-synuclein and polyunsaturated fatty acids promote clathrinmediated endocytosis and synaptic vesicle recycling. Traffic 10:218-234. CrossRef Medline

Bendor JT, Logan TP, Edwards RH (2013) The function of alpha-synuclein. Neuron 79:1044-1066. CrossRef Medline

Blondeau F, Ritter B, Allaire PD, Wasiak S, Girard M, Hussain NK, Angers A, Legendre-Guillemin V, Roy L, Boismenu D, Kearney RE, Bell AW, Bergeron JJ, McPherson PS (2004) Tandem MS analysis of brain clathrin-coated vesicles reveals their critical involvement in synaptic vesicle recycling. Proc Natl Acad Sci U S A 101:3833-3838. CrossRef Medline

Burré J, Sharma M, Tsetsenis T, Buchman V, Etherton MR, Südhof TC (2010) Alpha-synuclein promotes SNARE-complex assembly in vivo and in vitro. Science 329:1663-1667. CrossRef Medline

Burré J, Sharma M, Südhof TC (2012) Systematic mutagenesis of alphasynuclein reveals distinct sequence requirements for physiological and pathological activities. J Neurosci 32:15227-15242. CrossRef Medline

Cabin DE, Shimazu K, Murphy D, Cole NB, Gottschalk W, McIlwain KL, Orrison B, Chen A, Ellis CE, Paylor R, Lu B, Nussbaum RL (2002) Synaptic vesicle depletion correlates with attenuated synaptic responses to prolonged repetitive stimulation in mice lacking alpha-synuclein. J Neurosci 22:8797-8807. Medline

Chandra S (2009) Synucleins. In: The new encyclopedia of neuroscience, Vol. 9 (Squire L, ed.), pp 833-837. New York: Oxford Academic.

Chandra S, Chen X, Rizo J, Jahn R, Südhof TC (2003) A broken alpha-helix in folded alpha-Synuclein. J Biol Chem 278:15313-15318. CrossRef Medline

Chandra S, Fornai F, Kwon HB, Yazdani U, Atasoy D, Liu X, Hammer RE, Battaglia G, German DC, Castillo PE, Südhof TC (2004) Doubleknockout mice for alpha- and beta-synucleins: effect on synaptic functions. Proc Natl Acad Sci U S A 101:14966-14971. CrossRef Medline

Chandra S, Gallardo G, Fernández-Chacón R, Schlüter OM, Südhof TC (2005) Alpha-synuclein cooperates with CSPalpha in preventing neurodegeneration. Cell 123:383-396. CrossRef Medline

Cheng F, Li X, Li Y, Wang C, Wang T, Liu G, Baskys A, Uéda K, Chan P, Yu S (2011) alpha-Synuclein promotes clathrin-mediated NMDA receptor endocytosis and attenuates NMDA-induced dopaminergic cell death. J Neurochem 119:815-825. CrossRef Medline

Choi BK, Choi MG, Kim JY, Yang Y, Lai Y, Kweon DH, Lee NK, Shin YK (2013) Large alpha-synuclein oligomers inhibit neuronal SNAREmediated vesicle docking. Proc Natl Acad Sci U S A 110:4087-4092. CrossRef Medline

Clayton DF, George JM (1999) Synucleins in synaptic plasticity and neurodegenerative disorders. J Neurosci Res 58:120-129. CrossRef Medline

Cooper AA, Gitler AD, Cashikar A, Haynes CM, Hill KJ, Bhullar B, Liu K, Xu K, Strathearn KE, Liu F, Cao S, Caldwell KA, Caldwell GA, Marsischky G, Kolodner RD, Labaer J, Rochet JC, Bonini NM, Lindquist S (2006) Alpha-synuclein blocks ER-Golgi traffic and Rab1 rescues neuron loss in Parkinson's models. Science 313:324-328. CrossRef Medline

Cremona O, Di Paolo G, Wenk MR, Lüthi A, Kim WT, Takei K, Daniell L, Nemoto Y, Shears SB, Flavell RA, McCormick DA, De Camilli P (1999) Essential role of phosphoinositide metabolism in synaptic vesicle recycling. Cell 99:179-188. CrossRef Medline

Darios F, Ruipérez V, López I, Villanueva J, Gutierrez LM, Davletov B (2010) Alpha-synuclein sequesters arachidonic acid to modulate SNAREmediated exocytosis. EMBO Rep 11:528-533. CrossRef Medline

Deák F, Schoch S, Liu X, Südhof TC, Kavalali ET (2004) Synaptobrevin is essential for fast synaptic-vesicle endocytosis. Nat Cell Biol 6:1102-1108. CrossRef Medline

Devine MJ, Gwinn K, Singleton A, Hardy J (2011) Parkinson's disease and alpha-synuclein expression. Mov Disord 26:2160-2168. CrossRef Medline

DeWitt DC, Rhoades E (2013) alpha-Synuclein Can Inhibit SNAREMediated Vesicle Fusion through Direct Interactions with Lipid Bilayers. Biochemistry 52:2385-2387. CrossRef Medline

Diao J, Burré J, Vivona S, Cipriano DJ, Sharma M, Kyoung M, Südhof TC, Brunger AT (2013) Native $\alpha$-synuclein induces clustering of synapticvesicle mimics via binding to phospholipids and synaptobrevin-2/ VAMP2. Elife 2:e00592. CrossRef Medline

Di Paolo G, Sankaranarayanan S, Wenk MR, Daniell L, Perucco E, Caldarone BJ, Flavell R, Picciotto MR, Ryan TA, Cremona O, De Camilli P 
(2002) Decreased synaptic vesicle recycling efficiency and cognitive deficits in amphiphysin 1 knockout mice. Neuron 33:789-804. CrossRef Medline

Dittman J, Ryan TA (2009) Molecular circuitry of endocytosis at nerve terminals. Annu Rev Cell Dev Biol 25:133-160. CrossRef Medline

Edvardson S, Cinnamon Y, Ta-Shma A, Shaag A, Yim YI, Zenvirt S, Jalas C, Lesage S, Brice A, Taraboulos A, Kaestner KH, Greene LE, Elpeleg O (2012) A deleterious mutation in DNAJC6 encoding the neuronalspecific clathrin-uncoating co-chaperone auxilin, is associated with juvenile parkinsonism. PLoS One 7:e36458. CrossRef Medline

Ferguson SM, Brasnjo G, Hayashi M, Wölfel M, Collesi C, Giovedi S, Raimondi A, Gong LW, Ariel P, Paradise S, O’toole E, Flavell R, Cremona O, Miesenböck G, Ryan TA, De Camilli P (2007) A selective activitydependent requirement for dynamin 1 in synaptic vesicle endocytosis. Science 316:570-574. CrossRef Medline

Ferreon AC, Gambin Y, Lemke EA, Deniz AA (2009) Interplay of alphasynuclein binding and conformational switching probed by singlemolecule fluorescence. Proc Natl Acad Sci U S A 106:5645-5650. CrossRef Medline

Granseth B, Odermatt B, Royle SJ, Lagnado L (2006) Clathrin-mediated endocytosis is the dominant mechanism of vesicle retrieval at hippocampal synapses. Neuron 51:773-786. CrossRef Medline

Greten-Harrison B, Polydoro M, Morimoto-Tomita M, Diao L, Williams AM, Nie EH, Makani S, Tian N, Castillo PE, Buchman VL, Chandra SS (2010) alphabetagamma-Synuclein triple knockout mice reveal agedependent neuronal dysfunction. Proc Natl Acad Sci U S A 107:1957319578. CrossRef Medline

Houlden H, Singleton AB (2012) The genetics and neuropathology of Parkinson's disease. Acta Neuropathol 124:325-338. CrossRef Medline

Huttner WB, Schiebler W, Greengard P, De Camilli P (1983) Synapsin I (protein I), a nerve terminal-specific phosphoprotein. III. Its association with synaptic vesicles studied in a highly purified synaptic vesicle preparation. J Cell Biol 96:1374-1388. CrossRef Medline

Jao CC, Der-Sarkissian A, Chen J, Langen R (2004) Structure of membranebound alpha-synuclein studied by site-directed spin labeling. Proc Natl Acad Sci U S A 101:8331-8336. CrossRef Medline

Jensen MB, Bhatia VK, Jao CC, Rasmussen JE, Pedersen SL, Jensen KJ, Langen R, Stamou D (2011) Membrane curvature sensing by amphipathic helices: a single liposome study using alpha-synuclein and annexin B12. J Biol Chem 286:42603-42614. CrossRef Medline

Jin J, Li GJ, Davis J, Zhu D, Wang Y, Pan C, Zhang J (2007) Identification of novel proteins associated with both alpha-synuclein and DJ-1. Mol Cell Proteomics 6:845-859. CrossRef Medline

Kisos H, Ben-Gedalya T, Sharon R (2014) The clathrin-dependent localization of dopamine transporter to surface membranes is affected by alphasynuclein. J Mol Neurosci 52:167-176. CrossRef Medline

Koo SJ, Markovic S, Puchkov D, Mahrenholz CC, Beceren-Braun F, Maritzen T, Dernedde J, Volkmer R, Oschkinat H, Haucke V (2011) SNARE motif-mediated sorting of synaptobrevin by the endocytic adaptors clathrin assembly lymphoid myeloid leukemia (CALM) and AP180 at synapses. Proc Natl Acad Sci U S A 108:13540-13545. CrossRef Medline

Krebs CE, Karkheiran S, Powell JC, Cao M, Makarov V, Darvish H, Di Paolo G, Walker RH, Shahidi GA, Buxbaum JD, De Camilli P, Yue Z, PaisánRuiz C (2013) The Sac1 domain of SYNJ1 identified mutated in a family with early-onset progressive Parkinsonism with generalized seizures. Hum Mutat 34:1200-1207. CrossRef Medline

Kuwahara T, Koyama A, Koyama S, Yoshina S, Ren CH, Kato T, Mitani S, Iwatsubo T (2008) A systematic RNAi screen reveals involvement of endocytic pathway in neuronal dysfunction in alpha-synuclein transgenic $\mathrm{C}$. elegans. Hum Mol Genet 17:2997-3009. CrossRef Medline

Kwon SE, Chapman ER (2011) Synaptophysin regulates the kinetics of synaptic vesicle endocytosis in central neurons. Neuron 70:847-854. CrossRef Medline

Larsen KE, Schmitz Y, Troyer MD, Mosharov E, Dietrich P, Quazi AZ, Savalle M, Nemani V, Chaudhry FA, Edwards RH, Stefanis L, Sulzer D (2006) Alpha-synuclein overexpression in PC12 and chromaffin cells impairs catecholamine release by interfering with a late step in exocytosis. J Neurosci 26:11915-11922. CrossRef Medline

Li J, Henning Jensen P, Dahlström A (2002) Differential localization of alpha-, beta- and gamma-synucleins in the rat CNS. Neuroscience 113: 463-478. CrossRef Medline

Lill CM, Roehr JT, McQueen MB, Kavvoura FK, Bagade S, Schjeide BM,
Schjeide LM, Meissner E, Zauft U, Allen NC, Liu T, Schilling M, Anderson KJ, Beecham G, Berg D, Biernacka JM, Brice A, DeStefano AL, Do CB, Eriksson N, et al. (2012) Comprehensive research synopsis and systematic meta-analyses in Parkinson's disease genetics: The PDGene database. PLoS Genet 8:e1002548. CrossRef Medline

Mani M, Lee SY, Lucast L, Cremona O, Di Paolo G, De Camilli P, Ryan TA (2007) The dual phosphatase activity of synaptojanin1 is required for both efficient synaptic vesicle endocytosis and reavailability at nerve terminals. Neuron 56:1004-1018. CrossRef Medline

Matta S, Van Kolen K, da Cunha R, van den Bogaart G, Mandemakers W, Miskiewicz K, De Bock PJ, Morais VA, Vilain S, Haddad D, Delbroek L, Swerts J, Chávez-Gutiérrez L, Esposito G, Daneels G, Karran E, Holt M, Gevaert K, Moechars DW, De Strooper B, et al. (2012) LRRK2 controls an EndoA phosphorylation cycle in synaptic endocytosis. Neuron 75 : 1008-1021. CrossRef Medline

Maycox PR, Link E, Reetz A, Morris SA, Jahn R (1992) Clathrin-coated vesicles in nervous tissue are involved primarily in synaptic vesicle recycling. J Cell Biol 118:1379-1388. CrossRef Medline

Milosevic I, Giovedi S, Lou X, Raimondi A, Collesi C, Shen H, Paradise S, O’Toole E, Ferguson S, Cremona O, De Camilli P (2011) Recruitment of endophilin to clathrin-coated pit necks is required for efficient vesicle uncoating after fission. Neuron 72:587-601. CrossRef Medline

Mizuno N, Varkey J, Kegulian NC, Hegde BG, Cheng N, Langen R, Steven AC (2012) Remodeling of lipid vesicles into cylindrical micelles by alphasynuclein in an extended alpha-helical conformation. J Biol Chem 287: 29301-29311. CrossRef Medline

Nalls MA, Plagnol V, Hernandez DG, Sharma M, Sheerin UM, Saad M, Simón-Sánchez J, Schulte C, Lesage S, Sveinbjörnsdóttir S, Stefánsson K, Martinez M, Hardy J, Heutink P, Brice A, Gasser T, Singleton AB, Wood NW (2011) Imputation of sequence variants for identification of genetic risks for Parkinson's disease: a meta-analysis of genome-wide association studies. Lancet 377:641-649. CrossRef Medline

Narayanan V, Scarlata S (2001) Membrane binding and self-association of alpha-synucleins. Biochemistry 40:9927-9934. CrossRef Medline

Nemani VM, Lu W, Berge V, Nakamura K, Onoa B, Lee MK, Chaudhry FA, Nicoll RA, Edwards RH (2010) Increased expression of alpha-synuclein reduces neurotransmitter release by inhibiting synaptic vesicle reclustering after endocytosis. Neuron 65:66-79. CrossRef Medline

Ninkina N, Peters OM, Connor-Robson N, Lytkina O, Sharfeddin E, Buchman VL (2012) Contrasting effects of alpha-synuclein and gammasynuclein on the phenotype of cysteine string protein alpha (CSPalpha) null mutant mice suggest distinct function of these proteins in neuronal synapses. J Biol Chem 287:44471-44477. CrossRef Medline

Payton JE, Perrin RJ, Clayton DF, George JM (2001) Protein-protein interactions of alpha-synuclein in brain homogenates and transfected cells. Brain Res Mol Brain Res 95:138-145. CrossRef Medline

Pranke IM, Morello V, Bigay J, Gibson K, Verbavatz JM, Antonny B, Jackson CL (2011) alpha-Synuclein and ALPS motifs are membrane curvature sensors whose contrasting chemistry mediates selective vesicle binding. J Cell Biol 194:89-103. CrossRef Medline

Raimondi A, Ferguson SM, Lou X, Armbruster M, Paradise S, Giovedi S, Messa M, Kono N, Takasaki J, Cappello V, O’Toole E, Ryan TA, De Camilli P (2011) Overlapping role of dynamin isoforms in synaptic vesicle endocytosis. Neuron 70:1100-1114. CrossRef Medline

Rozas JL, Gómez-Sánchez L, Mircheski J, Linares-Clemente P, NietoGonzález JL, Vázquez ME, Luján R, Fernández-Chacón R (2012) Motorneurons require cysteine string protein-alpha to maintain the readily releasable vesicular pool and synaptic vesicle recycling. Neuron 74:151165. CrossRef Medline

Saheki Y, De Camilli P (2012) Synaptic vesicle endocytosis. Cold Spring Harb Perspect Biol 4: a005645. Medline

Scott D, Roy S (2012) alpha-Synuclein inhibits intersynaptic vesicle mobility and maintains recycling-pool homeostasis. J Neurosci 32:1012910135. CrossRef Medline

Sharma M, Burré J, Südhof TC (2011) CSPalpha promotes SNAREcomplex assembly by chaperoning SNAP-25 during synaptic activity. Nat Cell Biol 13:30-39. CrossRef Medline

Spillantini MG, Schmidt ML, Lee VM, Trojanowski JQ, Jakes R, Goedert M (1997) Alpha-synuclein in Lewy bodies. Nature 388:839-840. CrossRef Medline

Sudhof TC (2004) The synaptic vesicle cycle. Annu Rev Neurosci 27:509_ 547. CrossRef Medline 
Trempe JF, Chen CX, Grenier K, Camacho EM, Kozlov G, McPherson PS, Gehring K, Fon EA (2009) SH3 domains from a subset of BAR proteins define a Ubl-binding domain and implicate parkin in synaptic ubiquitination. Mol Cell 36:1034-1047. CrossRef Medline

Varkey J, Isas JM, Mizuno N, Jensen MB, Bhatia VK, Jao CC, Petrlova J, Voss JC, Stamou DG, Steven AC, Langen R (2010) Membrane curvature induction and tubulation are common features of synucleins and apolipoproteins. J Biol Chem 285:32486-32493. CrossRef Medline

Volpicelli-Daley LA, Lucast L, Gong LW, Liu L, Sasaki J, Sasaki T, Abrams CS, Kanaho Y, De Camilli P (2010) Phosphatidylinositol-4-phosphate 5-kinases and phosphatidylinositol 4,5-bisphosphate synthesis in the brain. J Biol Chem 285:28708-28714. CrossRef Medline
Westphal CH, Chandra SS (2013) Monomeric synucleins generate membrane curvature. J Biol Chem 288:1829-1840. CrossRef Medline

Woods WS, Boettcher JM, Zhou DH, Kloepper KD, Hartman KL, Ladror DT, QiZ, Rienstra CM, George JM (2007) Conformation-specific binding of alpha-synuclein to novel protein partners detected by phage display and NMR spectroscopy. J Biol Chem 282:34555-34567. CrossRef Medline

Yim YI, Sun T, Wu LG, Raimondi A, De Camilli P, Eisenberg E, Greene LE (2010) Endocytosis and clathrin-uncoating defects at synapses of auxilin knockout mice. Proc Natl Acad Sci U S A 107:4412-4417. CrossRef Medline Zhang YQ, Henderson MX, Colangelo CM, Ginsberg SD, Bruce C, Wu T, Chandra SS (2012) Identification of CSPalpha clients reveals a role in dynamin 1 regulation. Neuron 74:136-150. CrossRef Medline 